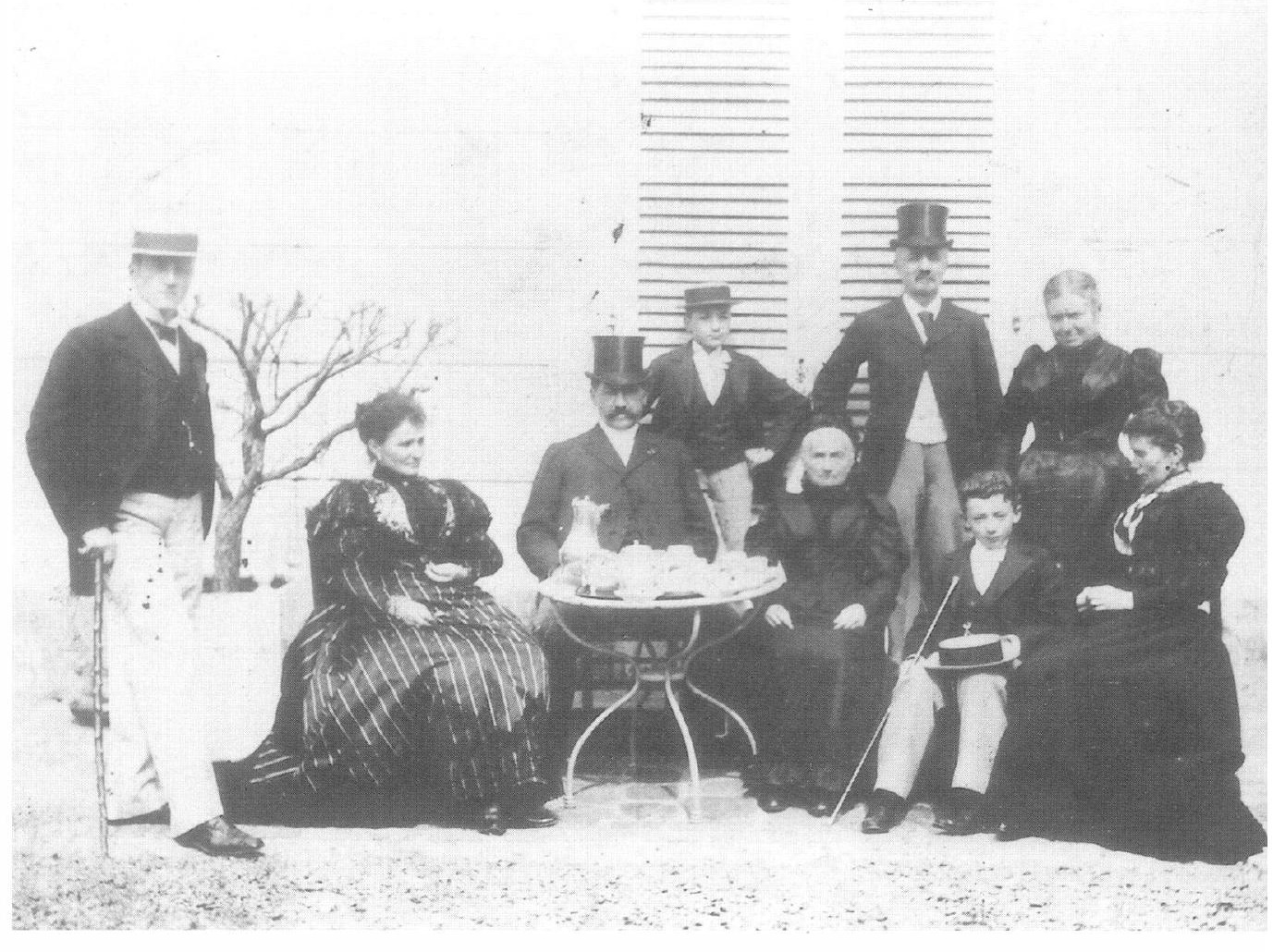

Ein Familienbild. Stehend vor der Fassade: Vater Alexandre und Bruder Albert, sitzend rechts die Mutter Amélie, neben ihr Paul Reynaud. Um 1890.

Privatbesitz Madame Evelyne Demey 


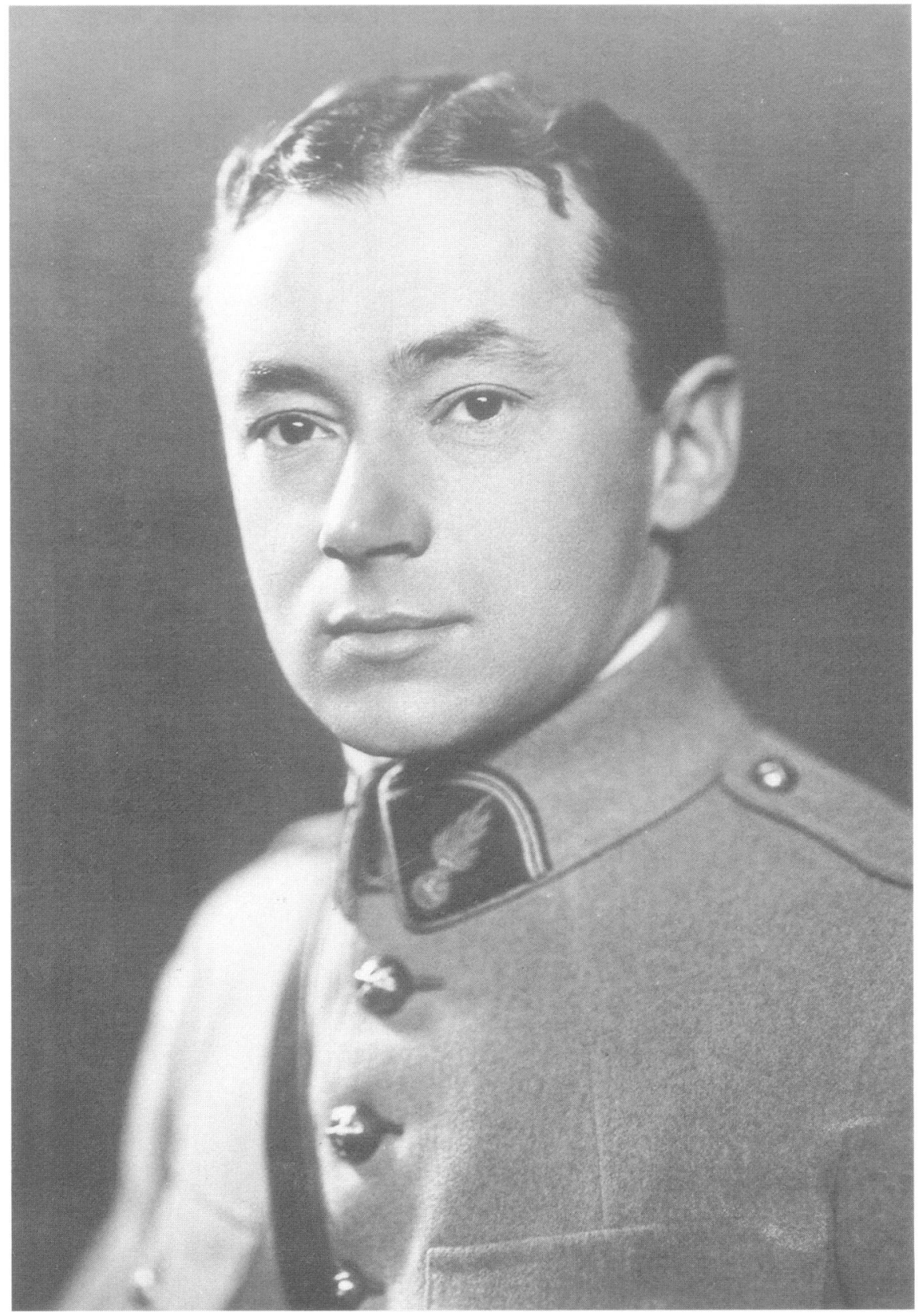

Als Soldat im Ersten Weltkries.

service listorigue de l'Armede derre, Vincennes 


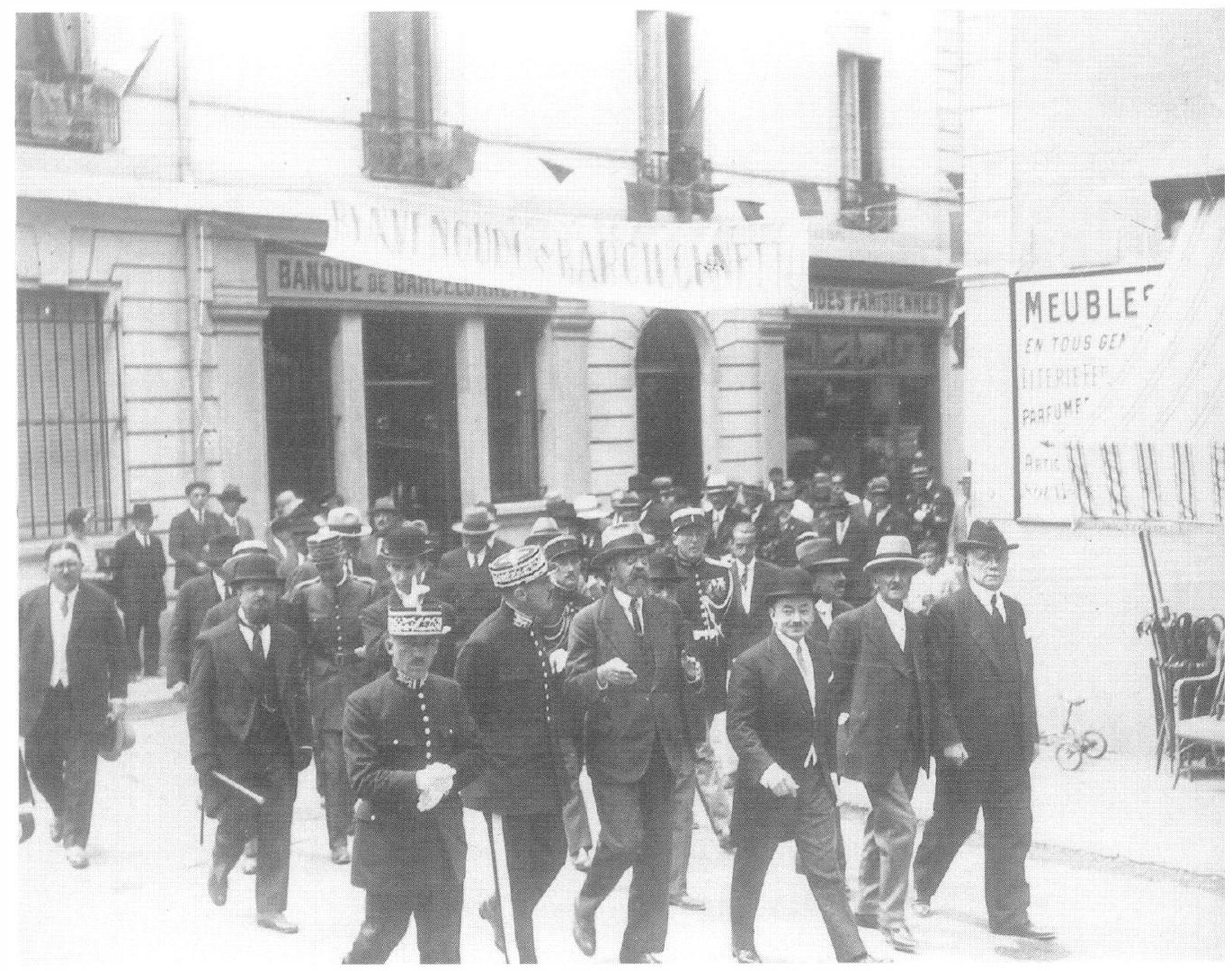

Beim Festzug aus Anlaß des 700. Jahrestags der Gründung von Barcelonnette. Reynaud wird flankiert von Senator André Honnorat (links), Bürgermeister Rémy Reynaud und Conseiller Général Paul Gassier (rechts), August 1931. Musée de la Vallée, Barcelonnette 


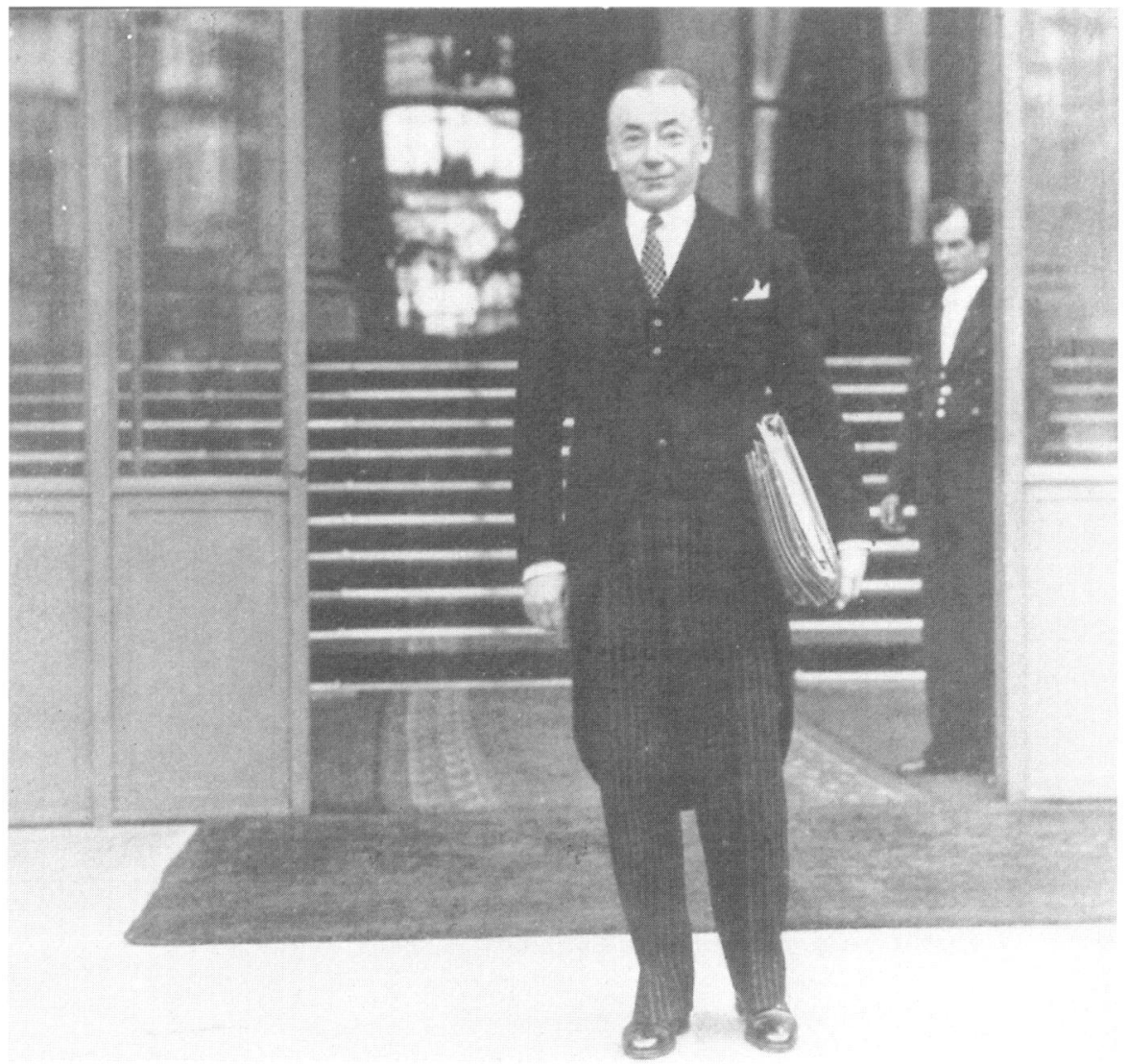

Revnaud verläßt den Élysćc-Palast, nachdem Staatspräsident Lebrun seine „Décrets-lois" zur Neuorientierung der Wirtschafts- und Finanzpolitik unterzeichnet hat, 12. November 1938.

Flammarion, Paris 


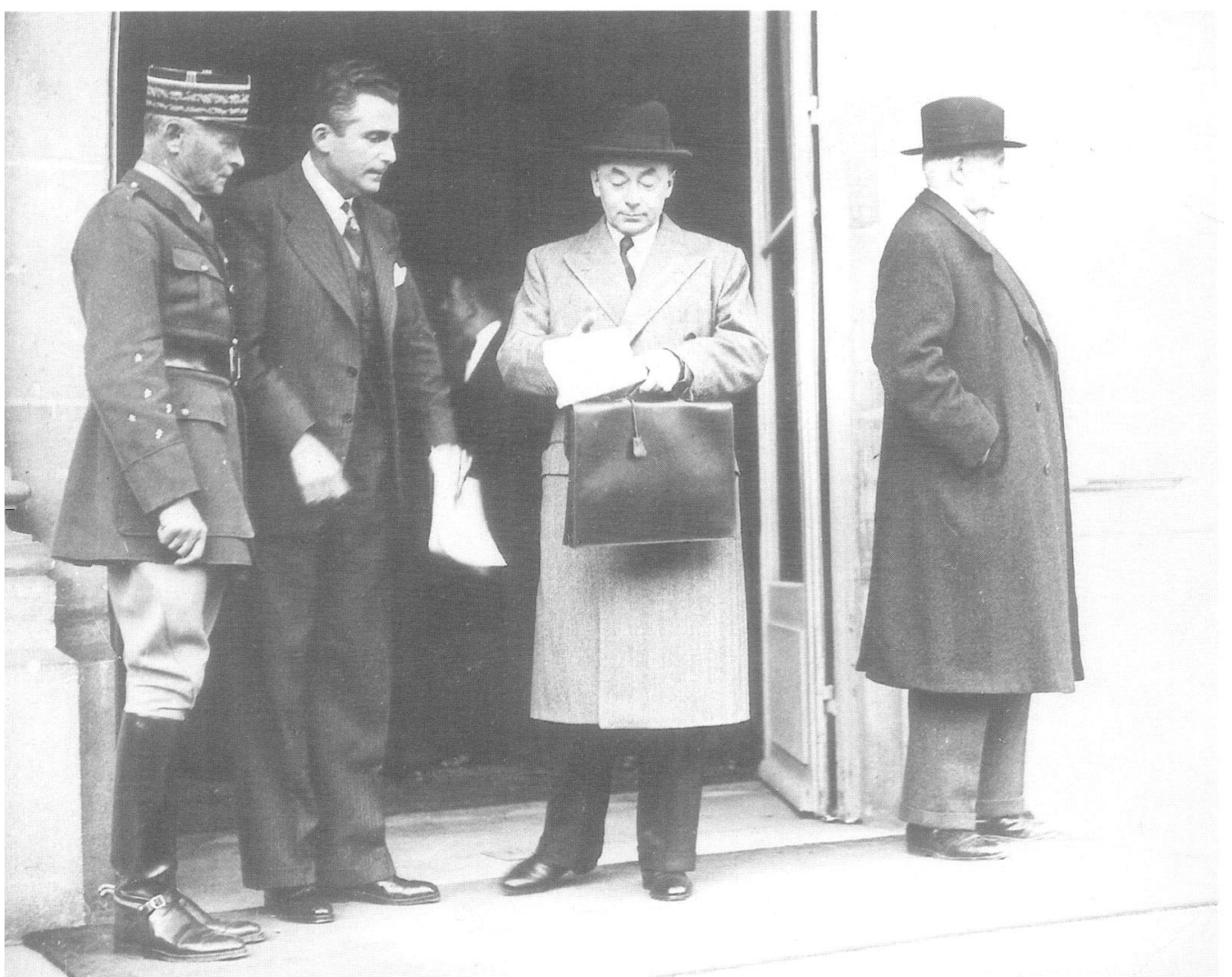

Nach Ende ciner Besprechung am 21. Mai 1940. Von links nach rechts: General Weygand, Paul Baudouin, Paul Reynaud, Marschall Pétain.

Agence Keystone, Paris 


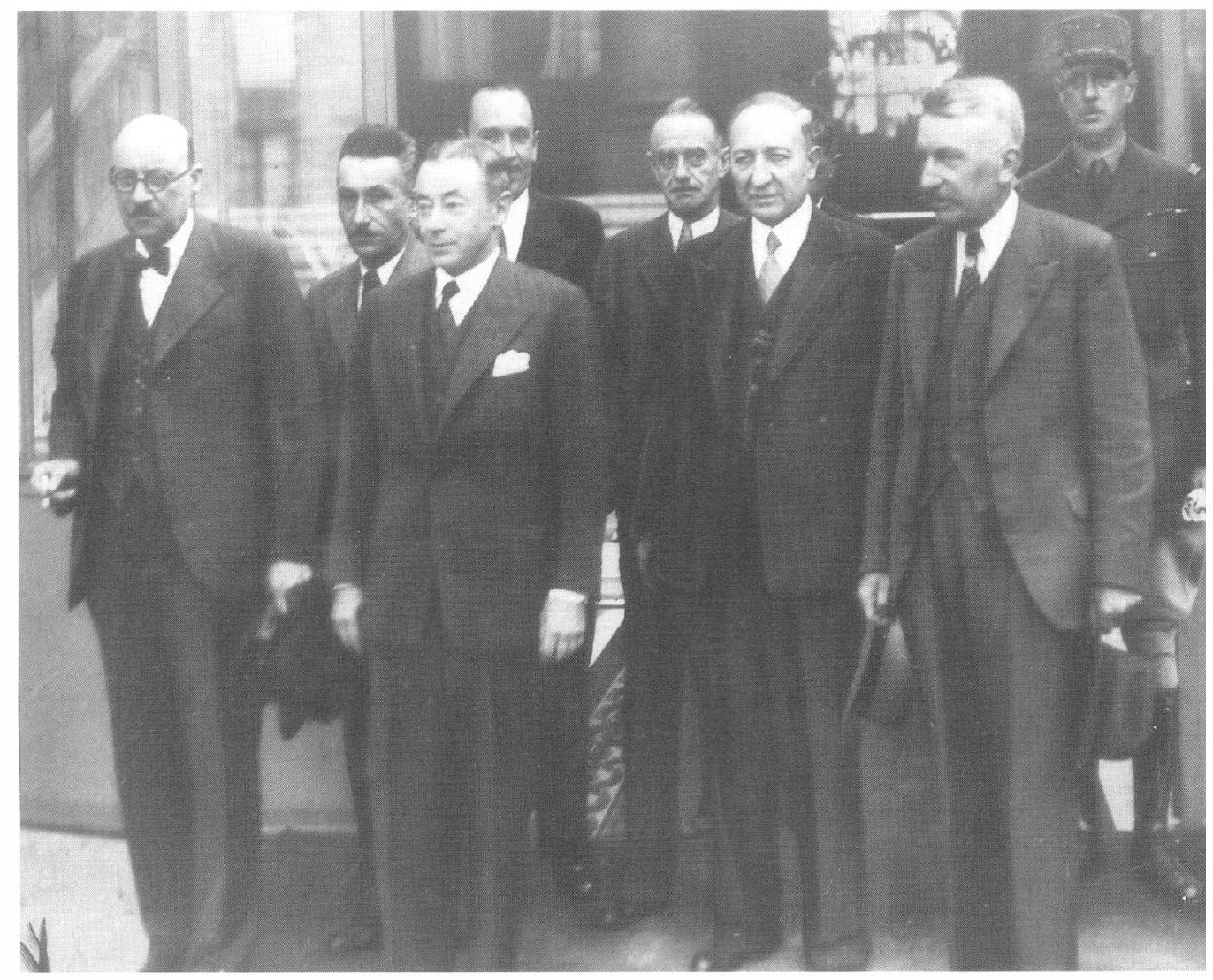

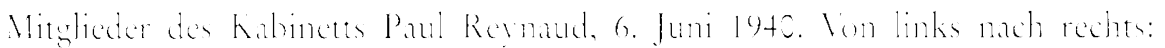

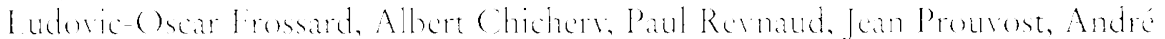

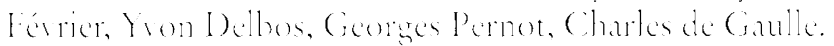

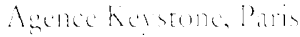




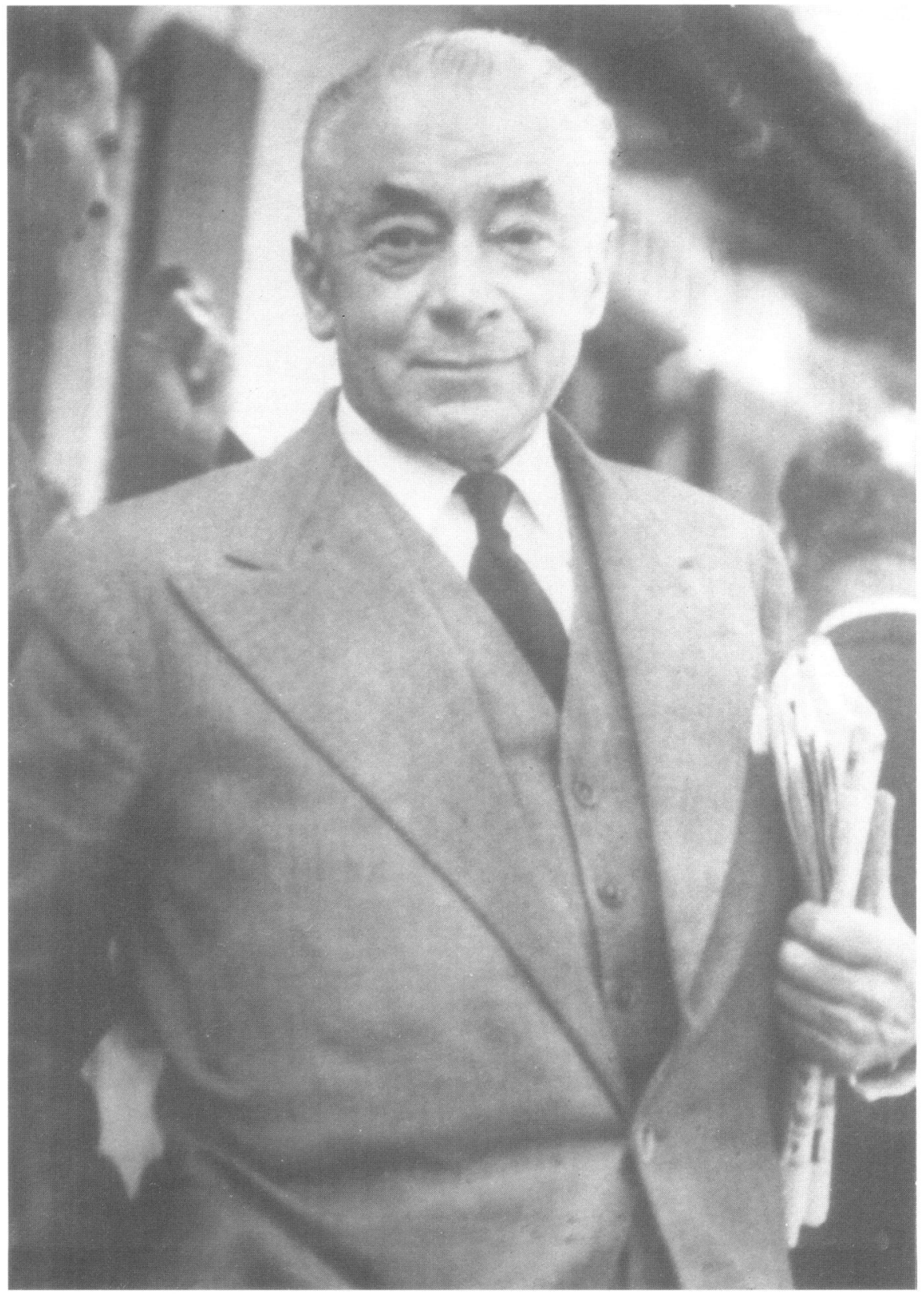

Paul Revnaud in seinen letyen Lebensiahren.

Privatbesity Madame Frelone I bemes 


\section{Die Bewährung in der Regierungsverantwortung: Finanzminister im zweiten Kabinett Tardieu 1930 - Kolonialminister unter Laval 1931/32}

\section{Personelle Konstellation und politische Ausgangslage}

André Tardieu gehörte zu den herausragendsten politischen Figuren der Dritten Republik, vor dessen Begabung und Format selbst der nicht durch mangelndes Selbstbewußtsein gehemmte Reynaud sich eingestandenermaßen mit der Rolle des „treuen Zweiten " zufriedengab.1 Dem Milieu der Pariser Großbourgeoisie entstammend, hatte der um zwei Jahre Ältere dank seiner vielseitigen Fähigkeiten und der weitreichenden Beziehungen seiner Familie den Weg in die Politik auf vergleichsweise unkonventionelle Art gefunden. Jeweils Jahrgangsbester in den Concours für die Aufnahme in die „Ecole Normale Supérieure“ bzw. den diplomatischen Dienst, hatte er als 22jähriger 1899 beide Optionen zugunsten einer Tätigkeit im Umfeld Waldeck-Rousseaus aufgegeben. Nach 1901 erwarb er sich als politischer Journalist und Verfasser außenpolitischer Leitartikel zunächst für Le Figaro, schließlich für Le Temps den Ruf eines versierten und gewichtigen Kommentators internationaler Politik. Der Ausbruch des Ersten Weltkriegs unterbrach die politische Karriere Tardieus, der im April 1914 unter liberaler Etikettierung zum Abgeordneten des Départements Seine-et-Oise gewählt worden war, nur kurz. Nach nur knapp einjährigem Dienst in der Entourage Fochs und als Kompaniechef an der Front kehrte er 1915 ins Parlament zurück. Im Juni 1917 verließ er Frankreich als neuer Hochkommissar in den USA mit der Aufgabe der Koordination der Kriegsanstrengungen beider Staaten. Das Vertrauen Clemenceaus, das er sich im Rahmen dieser Tätigkeit erwarb, führte Tardieu ab Ende 1918 an die Spitze des Expertenkomitees zur Vorbereitung der französischen Vorschläge für die Friedenskonferenz; an deren Beratungen nahm er als einer der Vertreter Frankreichs teil.

Seinen Ruf als Gefolgsmann des "Tigers“, in dessen Regierung er ab November 1919 für kurze Zeit das Amt des Ministers für die befreiten Regionen innehatte, befestigte er in den Folgejahren durch eine publizistisch-parlamentarische Kampagne zugunsten der rigiden Durchsetzung der Versailler Vertragsbestimmungen. Sie brachte ihn während der Legislaturperiode 1919-24 in Gegensatz zu Briand, Millerand und Poincaré. Die polemische Schärfe seiner Sprache und die Härte der ausgesprochenen Verdikte gegen Politiker der Mitte und der parlamentarischen

1 Reynaud an Tardicu, 13. 7. 1932 (AN, 324 AP 133). 
Linken machten ihn wie Georges Mandel - dieser ebenfalls ein ehemaliger Mitarbeiter Clemenceaus - zum Außenseiter im politischen Leben Frankreichs der frühen zwanziger Jahre. In der Folge verlor Tardieu 1924 sein Parlamentsmandat, gewann es allerdings bereits 1926 bei Nachwahlen in Belfort nach fulminantem Wahlkampf zurück. Im gleichen Jahr trat er als Minister für öffentliche Arbeiten, schließlich ab 1928 als Innenminister im Kabinett Poincaré in eine neue, gemäßigtere Zwischenphase seines politischen Lebens. Bis Juni 1932 blieb er nun fast ununterbrochen als Minister verschiedener Ressorts oder als Regierungschef an den Schalthebeln der Macht. Mit Beginn seiner Kabinettstätigkeit bereits und nicht erst ab 1934, als er mit seinen Ideen zur Staatsreform verstärkt an die Öffentlichkeit trat, leitete er Maßnahmen zur strukturellen Modernisierung Frankreichs in die Wege, zunächst insbesondere auf dem Gebiet des Verkehrswesens. Konsequent stellte Tardieu seine drei Ministerpräsidentschaften - von November 1929 bis Februar 1930, von März bis Dezember 1930 und von Februar bis Mai 1932 unter das leitende Motiv einer umfassenden Erneuerung Frankreichs. ${ }^{2}$

Durch Poincaré als Nachfolger „designiert“ und unterstützt von der Mehrheit der gemäßigten Rechten bis hinein in den rechten Flügel der Radikalsozialisten, gelangte Tardieu erst nach einer der längsten Regierungskrisen der Dritten Republik in sein neues Amt. ${ }^{3}$ Zum bevorzugten, als Prototyp des „Reaktionärs“ gebrandmarkten Gegner der Linken war er spätestens seit seiner Innenministerzeit geworden. Seither war in deren Reihen zum ohnehin genährten latenten Mißtrauen gegen den privilegierten, provozierenden Repräsentanten der „dynasties bourgeoises“ die offene Feindschaft gegen den erklärten Gegner der revolutionären Arbeiterbewegung getreten, der im Vorfeld der Maikundgebungen des Jahres 1929 vor autoritärer Repressionspolitik nicht zurückgescheut hatte. ${ }^{4}$ Die Daueropposition der Radikalsozialisten, die sich als stärkste Kammerfraktion zunächst seiner Berufung, schließlich seinen Reformplänen widersetzten, führte zum raschen Sturz seines ersten Kabinetts nach nur drei Monaten. Sie stellte darüber hinaus alle drei Amtszeiten unter einen ungünstigen Stern. ${ }^{5}$

Als Paul Reynaud am 2. März 1930 zum Finanzminister im zweiten Kabinett Tardieu berufen wurde, fand er eine komplexe innen- und finanzpolitische Situation vor, geprägt von den Vorgaben und den Umständen des Sturzes der ersten Regierung Tardieu sowie durch deren finanzpolitisches Erbe. Hierzu zählten in erster Linie die anstehende parlamentarische Durchsetzung eines ehrgeizigen Er-

2 Zum äußeren Werdegang Tardieus vgl. Monnet, Refaire la République, bes. S. 49-72; als neuere Handbuchdarstellungen: Nicolas Roussellier, Tardieu André, in: Jean-François Sirinelli (Hg.), Dictionnaire historique de la vie politique française au XXe siècle, Paris 1995, S. 1001-1003; Adrian Rossiter, Tardieu, André, in: David S. Bell/Douglas Johnson/Peter Morris (Hg.), Biographical Dictionary of French Political Leaders since 1870, New York u. a. 1990, S. 408-410.

3 Die Krise dauerte ganze siebzehn Tage, während derer sowohl das Projekt einer Linkskoalition mit sozialistischer Beteiligung unter Daladier als auch dasjenige einer radikalsozialistisch dominierten Regierung Clémentel schließlich der Mitte-Rechtskoalition Tardieus weichen mußten.

Zur „Designation“ durch Poincaré und zu Tardieus Klientel im Parlament vgl. Louis Latzarus, „La situation de M. Tardieu“, in: Revue Hebdomadaire, 9. 4. 1927, S. 246-248; Monnet, Refaire la République, S. $100 \mathrm{f}$.

4 Zu Tardieus Innenministerzeit: Monnet, Refaire la République, S. 58.

5 Zur Haltung des Parti Radical gegenüber den ersten beiden Kabinetten Tardieus vgl. Berstein, Parti Radical II, S. 154-157 und 160-167. 
neuerungsprogramms in Verbindung mit einer großangelegten Steuerreform. ${ }^{6}$ Es wird sich im folgenden zeigen, daß diese erste Ministerzeit Reynauds aufgrund mannigfacher sachgebotener und durch Kabinettsdisziplin auferlegter $Z$ wänge wohl jene Periode seines bisherigen politischen Lebens darstellte, die ihm am wenigsten Freiräume zur Entwicklung eigenständiger Ansätze ließ.

Das fünftägige Intermezzo der Regierung des radikalsozialistischen Parteichefs Camille Chautemps - Tardieu stürzte am 17. Februar, Chautemps amtierte vom 21. bis 25. des Monats - hatte die programmatischen Dispositionen Tardieus nicht grundlegend verändert, dessen Aussichten auf eine Fortsetzung seiner Arbeit nicht vermindert. Ohnehin hätte der Ministerpräsident bereits im November 1929 eine spätere Berufung vorgezogen, da er hoffte, nach der raschen „Abnutzung" einer Linksregierung um so dauerhafter an der Macht zu bleiben.7 Ein „Zwischenakt Chautemps" galt deshalb nach dem Sturz Tardieus in dessen Umgebung als geradezu wünschenswert, um für die Zukunft die Option eines radikalsozialistisch dominierten Kabinetts weitestgehend auszuschließen. Auch Reynaud, einmal mehr nützlicher Helfer im Hintergrund, machte in diesem Sinne Stimmung und intervenierte erfolgreich bei Staatspräsident Doumergue, um eine entsprechende Lösung anzuregen. ${ }^{8}$

Die indirekte Stärkung Tardieus nach dem Scheitern seines Nachfolgers, die erreichte klare Scheidung von Anhängern und Gegnern des neuen Kabinetts und die auf seiten der Linken gewonnene Überzeugung, daß die Rückkehr zu einer am Vorbild des „Cartel des Gauches“ orientierten Koalition für die Dauer der Legislaturperiode endgültig unmöglich geworden sei ${ }^{9}$, legten den Grund für die erbitterten und nicht immer aus Sachfragen hinreichend gerechtfertigten innenpolitischen Auseinandersetzungen, in die Tardieu und sein Finanzminister in der Folge einzutreten hatten. Die besorgte Kampfansage Léon Blums vom März 1930 war symptomatisch für die Wahrnehmung des politischen Profils des neuen Kabinetts im Lager der Linken: „Avec ou sans Briand, [...] le second ministère [Tardieu, A.d.V.] est un gouvernement de réaction pure et simple. Il nous reporte à plus de cinquante ans en arrière. Ni Rouvier, ni Méline, ni M. Millerand au lendemain des élections du 16 novembre, ni M. Poincaré au lendemain du Congrès d'Angers, ni Tardieu lui-même il y a trois mois, n'avaient osé gouverner avec l'unanimité des

${ }_{6}^{6}$ Diese erste Finanzministerzeit Reynauds fand bisher in der vorliegenden wirtschafts- und finanzgeschichtlichen Literatur zur französischen Zwischenkriegszeit noch keine eingehendere Berücksichtigung. Hinweise finden sich bei Sauvy, Asselain, Caron.

7 Entsprechende Andeutungen hatte Tardieu gegenüber Hoesch und Curtius gemacht (Hoesch an AA, 23. 2. 1930; PA-AA, R 70721).

8 „M. Paul Reynaud, qui passe, au centre, pour un manoeuvrier très malin, expliquait hier à ses amis pourquoi il était à souhaiter: 1. que M. Tardieu ne fut pas rappelé tout de suite à l'Elysée ou, s'il était rappelé, qu'il n'acceptât pas tout de suite de constituer le nouveau Ministère; 2. que le Président de la République commençat par charger le président des radicaux socialistes, M. Chautemps de former le Cabinet. „Il est absolument nécessaire, déclarait M. Paul Reynaud, de „vider“ les radicaux socialistes pour commencer; ensuite le terrain sera déblayé. Tel a été le sens de ma conversation avec le Président de la République et tel est aussi, je crois pouvoir le dire, le sentiment intime de M. Tardieu. [...] Quand il sera ainsi bien évident qu'un gouvernement dirigé par les radicaux socialistes est impossible à constituer ou incapable de vivre, les radicaux socialistes nous ficheront un peu la paix." (Bericht der Sûreté vom 20. 2. 1930; AN, F712957).

9 Über diese Stimmungslage berichtete Botschafter von Hoesch nach entsprechenden Sondierungen und Gesprächen unter anderem mit Chautemps (Hoesch an AA, 27. 2. 1930; PA-AA, R 70721). 
droites, contre l'unanimité des gauches républicaines. [...] Entendu. Va pour la lutte. Nous y sommes prêts. " 10 Die Auffassung einer scharfen Polarisierung der politischen Landschaft auch im tieferen Sinne einer sich anbahnenden sozialkonservativen Wende dominierte die Einschätzung Blums: „Les chefs véritables du gouvernement, c'est-à-dire Tardieu, Maginot, Paul Reynaud, François-Poncet, ont pour objectif certain de préparer dans le Parlement et dans le pays une coupure politique nouvelle. Non plus le cartel et l'anticartel, non plus la majorité et l'opposition actuelles de la Chambre, mais une masse de conservation sociale d'un côté et la masse de transformation révolutionnaire de l'autre."11 Paul Reynaud als an zentraler Stelle agierender Verteidiger eines "régime de la propriété capitaliste" 12 - diese Kategorisierung sollte ihm von nun an auf Dauer anhaften.

A priori unter dem Verdacht der reaktionären Rückwendung stehend und deshalb weitgehend auf eine „unvermischte Rechtsmajorität"13 in der Kammer angewiesen, verwandte Tardieu während der Dauer seiner Amtszeit ein hohes Maß an Energie darauf, den ihm gegenüberstehenden „Linksblock“ personell zu schwächen und durch programmatisches Entgegenkommen zu spalten. ${ }^{14}$ Aus dieser Taktik erwuchs eine wesentliche finanzpolitische Vorgabe für die Arbeit Reynauds. Direkter Anlaß für die Ablösung Tardieus im Februar 1930 war die budgetpolitische Unnachgiebigkeit seines Finanzministers Henry Chéron gewesen, der sich geweigert hatte, einer durch die radikalsozialistisch dominierte Finanzkommission geforderten, großzügigeren Gestaltung des geplanten Gesetzes zur Schaffung einer Altersrente für ehemalige Kriegsteilnehmer zuzustimmen. Am Ursprung der aufbrechenden Dissonanzen hatte freilich ein tiefergreifender Konflikt finanztheoretischer Art gestanden: Gestützt auf einen laut eigenem Bekunden auf stattliche 18 Milliarden Francs angewachsenen Überschuß an staatlichen Mitteln, hatte Chéron eine Politik des Budgetgleichgewichts und der Staatsentschuldung gegenüber der bewußten Inkaufnahme eines Defizits favorisiert. Nach den Vorstellungen der Finanzkommission hätte es durch die Auflage einer neuen Staatsanleihe im Wert von 1,15 Milliarden finanziert werden sollen. Unnachgiebig betrachtete es Chéron hingegen als seine Pflicht, "d'épargner pour éviter l'emprunt. Peu m'importe qu'on m'ait critiqué si j'ai rempli ce devoir! [...] Oui, je monte la garde autour de ce trésor et je n'y laisserai pas porter atteinte." ${ }^{15} \mathrm{Als}$ er in

10 Léon Blum, „De cinquante ans en arrière“, in: Le Populaire, 3. 3. 1930. Wiederabgedruckt in: L'Oeuvre de Léon Blum. Band III,2 (1928-1934), Paris 1972, S. 240f. (Zitat S. 241).

$"$ Léon Blum, "L'intérêt présent du socialisme“, in: Le Populaire, 10. 5. 1930. Wiederabgedruckt in: Ebenda, S. 247-249 (Zitat: S. 247).

12 Ebenda, S. 248.

13 Hoesch an AA, 29. 12. 1929 (ADAP B XIII, Nr. 228, hier: S. 479).

14 Zum Werben Tardieus um „Abtrünnige“ aus der bürgerlichen Linken vgl. Hoesch an AA, 3.3. 1930 (PA-AA, R 70721; dort auch das Zitat).

15 So der Finanzminister in der entscheidenden Finanzdebatte vom 14. Februar 1930; zitiert nach Bonnefous, Histoire politique V, S. 12. Allgemein zur Haltung Chérons und zu den daran sich anschließenden Debatten in Finanzkommission und Plenum: Ebenda, S. 10-14. Die Vorbehalte gegen die Finanzpolitik Chérons blieben nicht auf die Opposition beschränkt, sondern reichten nach Informationen der "Sûreté" bis in das Umfeld Tardieus und die Beamtenschaft des Finanzministeriums; vgl. die Berichte „A. 1441. Politique financière“ vom 8. 2. 1930 und „A. 1578. Sur la politique financière de M. Chéron et à propos de 'La Retraite des Combattants'“, 12.2. 1930 (AN, F712957).

Zum Verlauf der Regierungskrise und zu den Gründen für den Sturz der ersten Regierung Tardieu auch: Hoesch an AA, 23. 2. 1930 (PA-AA, R 70721). 
Fortsetzung dieser Haltung und in Abwesenheit des Ministerpräsidenten am 17. Februar das Vertrauen der Kammer einforderte, stürzte das Kabinett über eine letztlich zweitrangige Budgetfrage.

Der Nachfolger Reynaud trat mit der Vorgabe einer flexibleren Handhabung des Prinzips des Budgetgleichgewichts an. Als das Finanzgesetz für das Haushaltsjahr 1930/31 schließlich am 14. April 1930 verabschiedet wurde, wies es tatsächlich kaum mehr Ähnlichkeit mit dem Gesetzesprojekt auf, das Henry Chéron bereits im März 1929 vorgelegt hatte. Nicht nur war auf Wunsch Tardieus und mit Einverständnis Reynauds der relativ unbedeutende Ausgabentitel aufgenommen worden, der im Februar so unverhältnismäßige Wirkung gezeitigt hatte. Nach über einjähriger Beratungszeit, unterbrochen durch vier Regierungskrisen, umfaßte der unter Chéron auf 48 Milliarden Francs veranschlagte Ausgabenbereich zudem eine um vier Milliarden höhere Summe. ${ }^{16}$ Erstmals seit 1926, als mit den Poincaréschen Stabilisierungsmaßnahmen ein nachhaltiger wirtschaftlicher Aufschwung eingesetzt hatte, der bis einschließlich des Budgetjahrs 1929/30 regelmäBig Haushaltsüberschüsse bewirkte, kehrte im Amtsjahr Reynauds das Defizit in die französischen Staatsfinanzen zurück. ${ }^{17}$ Ein Bündel von miteinander verflochtenen Faktoren war verantwortlich dafür: die von Modernisierungsoptimismus getragene Erhöhung der Staatsausgaben nicht nur auf Initiative der Regierung hin, zum einen; sie verband sich zum anderen mit erheblichen Einnahmeverlusten und den ersten Vorboten der großen Wirtschaftskrise. Jene spiegelten sich bereits im Verlauf des Jahres 1930 in deutlich nach unten verlaufenden Wirtschaftsindices. ${ }^{18}$ Unabweisbar aber ist auch, daß mit dem Abgang Chérons die Ära der Finanzpolitiker ,alter Schule“ ihr Ende gefunden hatte. ${ }^{19}$

Ziel der folgenden Darlegungen kann es nicht sein, ein umfassendes wirtschafts- und finanzhistorisches Resümee der knapp zehnmonatigen Amtszeit Reynauds zu bieten. Entsprechend der Erkenntnisabsicht dieser Arbeit sollen hingegen die politischen Voraussetzungen und Implikationen seines finanzpolitischen Handelns beleuchtet werden. Eine allmählich sich schließende „Schere“, die dem politischen Erneuerungswillen wachsende finanzpolitische Zwänge entgegenstellte, verminderte ehemals vorhandene, doch insbesondere im öffentlichen Bewußtsein noch fortwirkende Handlungsspielräume. Die verantwortliche politische Leitung des Finanzressorts gewann somit vermehrtes Gewicht gerade zu einem Zeitpunkt, da die seit 1929 eingeleitete Lockerung der Austeritätspolitik Poincarés aufgrund des bis dahin erzielten Aufschwungs endlich in größerem Umfange möglich schien.

16 Bonnefous, Histoire politique V, S. 24-27.

17 Eine Übersicht über die Entwicklung des französischen Staatshaushalts seit Ende des Ersten Weltkriegs mit genauen Zahlenangaben findet sich bei Sauvy, Histoire économique I, S. 363-376, Band III, S. 380 f. Hiervon abweichende Angaben über die Höhe der erwarteten Staatseinahmen für das Haushaltsjahr 1930/31 bietet Bonnefous, Histoire V, S. 26. Vgl. auch Kenneth Mouré, Managing the franc Poincaré. Economic understanding and political constraint in French monetary policy, 1928-1936, Cambridge 1991, S. 156-159; Michel Margairaz, L'Etat, les finances et l'économie. Histoire d'une conversion 1932-1952. 2 Bände, Paris 1991, hier: Band I, S. 37-39.

18 Sauvy, Histoire économique I, S. 369; Mouré, Managing, S. 159 f.

19 Sauvy, Histoire économique I, S. $116 \mathrm{f}$. 


\section{Finanzpolitik in Zeiten beginnender wirtschaftlicher Depression}

\section{a) "Politique de prospérité" und "Plan d'outillage national": Modernisierung im Zeichen der sich anbabnenden Krise}

Im Mittelpunkt der Regierungserklärung Tardieus vom 7. November 1929 hatte ein innerhalb von fünf Jahren umzusetzender „Plan d'outillage national“ gestanden. Er sah den genau spezifizierten Einsatz von fünf Milliarden Francs auf den Gebieten der Landwirtschaft, des Gesundheits- und Erziehungswesens sowie der Verkehrs- und Nachrichtenverbindungen vor. Das solcherart angeschnittene Thema bildete keineswegs ein willkürlich gewähltes Element publikumswirksamer Selbstdarstellung eines ehrgeizigen Regierungschefs: Seit geraumer Zeit bereits hatte die Erneuerungsbedürftigkeit der wirtschaftlichen Strukturen Frankreichs Eingang in den politischen Diskurs gefunden, insbesondere nachdem klar geworden war, daß der seit Vorkriegszeiten spürbare und durch Kriegseinwirkung eklatant verschärfte Nachholbedarf auch über regional begrenzte Wiederaufbauprogramme nicht hatte abgedeckt werden können. Kaum umsetzbar während der Perioden wirtschaftlicher Depression, geriet das Thema zur Chefsache, als mit Tardieu ein auf Modernisierungsfragen bereits „spezialisierter" Politiker antrat. Der Zustand der Staatsfinanzen schien das großangelegte Unterfangen zu rechtfertigen: Finanziert werden sollte das Vorhaben nicht durch die Ausgabe von Anleihen oder über Steuererhöhungen, sondern durch die Inanspruchnahme der seit 1928 angesammelten Überschüsse im Staatshaushalt. Unter der optimistischen Parole einer „politique de la prospérité“ kündigte Tardieu darüber hinaus wesentliche Steuererleichterungen in Höhe von 3,4 Milliarden Francs an und versprach unter anderem den Ausbau des Sozialversicherungswesens und allgemeine Maßnahmen zur Staatsreform. 20

Nur zwei Wochen nach dem „Schwarzen Freitag“ an der New Yorker Börse vom 25. Oktober 1929 der Öffentlichkeit vorgestellt, trug Tardieus Vorhaben den Stempel jener vordem „prosperierenden Welt" ${ }^{21}$, für die es erdacht worden war. Tatsächlich hatten sich ja die Krisenanzeichen, die sich in Deutschland, den Vereinigten Staaten und in Belgien bereits im Jahresverlauf 1929 in Form des Verfalls von Aktienwerten und des Rückgangs der Industrieproduktion verdichtet hatten, zu diesem Zeitpunkt in Frankreich noch kaum bemerkbar gemacht. Im Gegenteil, alle Indikatoren schienen zunächst noch darauf hinzudeuten, daß Frankreich weitgehend verschont bleiben würde. Der Industrieproduktionsindex erreichte

20 JO, Chambre des Députés, Débats parlementaires, Séance du 7 novembre 1929, S. 2999-3001 (Zitat: S. 3001). Zu den Reformplänen Tardieus allgemein: Sauvy, Histoire Economique I, S. 107-118 und 448 f.; Monnet, Refaire la République, S. 103-105 und 137-174; Julian Jackson, The politics of depression in France 1932-1936, Cambridge 1985, S. 23 und 32-34; Monique Clague, Vision and Myopia in the New Politics of André Tardieu, in: French Historical Studies 8 (1973/74), S. 105129. Zum "Plan d'outillage national“ bietet nach wie vor den detailliertesten Aufschluß: Pierre Saly, La politique des Grands travaux en France, 1929-1939, New York 1977 sowie Ders., La politique française des grands travaux 1929-1939 fut-elle keynésienne?, in: Revue économique 31 (1980), S. 706-742.

21 Jackson, Politics of depression, S. 23. 
im Juni 1930 einen neuen Höchststand seit Ende des Großen Krieges und sank erst ab Herbst des Jahres deutlich ab; besonderes Wachstum hatten insbesondere neue Industriezweige wie die Automobil-, die Elektro- und die Erdölbranche verbuchen können. Während in Deutschland und in den USA die Industrieproduktionsraten gegen Ende 1930 um 30\% gegenüber den Werten von 1929 zurückgegangen waren, betrug der Rückgang in Frankreich im gleichen Zeitraum nur 7\%. Die Preise im Einzelhandel stiegen dort nicht vor Dezember 1930 signifikant an, und selbst der Prozentsatz an Arbeitslosen, der in den USA bis Ende 1930 im Verlauf eines Jahres von 8,2 auf 14,5\% angewachsen war, nahm in Frankreich erst ab Oktober 1930 deutlich zu. 22

Tardieus „Plan d'outillage national“ war der Kammer der Abgeordneten am 25. November 1929 in Form eines Gesetzesvorschlags vorgelegt worden und bei der Opposition auf äußerst kritische Resonanz gestoßen. In der Folge wurden in der Kammer allein 124 Abänderungsvorschläge und drei Gegenprojekte aus den Reihen der Sozialisten, der Radikalsozialisten und der "Socialistes français“ diskutiert, bevor ein modifiziertes Regierungsprojekt am 8. Juli 1930 erneut ins Parlament gelangte. ${ }^{23}$ Zuvor hatten Tardieu und Reynaud in mehreren Anhörungen vor der den Plänen ablehnend gegenüberstehenden Finanzkommission das Projekt verteidigt - allerdings ohne dauerhaften Erfolg. Aufgrund der dilatorischen Taktik der Kommission und vorgezogenen, schier endlosen Plenumsdebatten über die tatsächlich zur Verfügung stehenden Mittel verzögerte sich die Beratung des Gesetzes bis in den November 1930 und konnte vor dem Sturz der Regierung Tardieu im Dezember nicht mehr abgeschlossen werden. Unter den folgenden Kabinetten Steeg und Laval zerfaserte das Projekt in eine Fülle von Einzelkrediten, die mit dem ursprünglichen Ensemble nurmehr entfernte Ähnlichkeit hatten. Bis Ende 1931 veränderte es schließlich seinen Charakter mehr und mehr in Richtung eines Investitionsprogramms zur Bekämpfung der Wirtschaftskrise. ${ }^{24}$

Reynauds Rolle während der Diskussionen in Finanzkommission und Plenum bestand aufgrund der Tatsache, daß das Projekt zur großen Verärgerung Tardieus niemals in seiner Gesamtheit und im einzelnen diskutiert wurde, nur zum Teil in der Offenlegung der geplanten Verwendung der vorgesehenen Mittel. ${ }^{25}$ Auch in den Reihen der Opposition nämlich gestand man durchaus die Notwendigkeit

22 Charles P. Kindleberger, The World in Depression, 1929-1939, Berkeley 1973, S. 116; Sauvy, Histoire économique I, S. 114-116, III, S. 305 und 315; Jackson, Politics of depression, S. $23 \mathrm{f}$; Mouré, Managing, S. 13; Braudel/Labrousse, Histoire économique et sociale IV/2, S. $646 \mathrm{ff}$. Ausgehend von frühen Krisenanzeichen in bestimmten, exportorientierten Industriezweigen zweifelt im Gegensatz zur übrigen Forschung an einem späteren Krisenbeginn in Frankreich: Jacques Marseille, Les origines ,inopportunes' de la crise de 1929 en France, in: Revue économique 31 (1980), S. 648-684; Ders., Crise de 1929, in: Jean-François Sirinelli (Hg.), Dictionnaire historique de la vie politique française au XXe siècle, Paris 1995, S. 238-241.

23 Vgl. JO, Chambre des Députés, Documents parlementaires, Annexe 2479: Projet de loi relatif au perfectionnement de l'outillage national; das revidierte Gesetzesprojekt findet sich in: JO, Chambre des Députés, Documents parlementaires, Annexe 3388, S. 844-846.

24 Monnet, Refaire la République, S. 140-143; Bonnefous, Histoire politique V, S. 39-42; Jackson, Politics of depression, S. $31 \mathrm{f}$.

25 Zur Haltung Reynauds vgl. insbesondere seine Stellungnahmen in den Kammerdebatten vom 26., 27., 28. November sowie vom 4. Dezember 1930 (JO, Chambre des Députés, Débats parlementaires, Séance du 26 novembre 1930, S. 3585-3589; Ebenda, Séance du 27 novembre 1930, S. 35943606; Ebenda, $1^{\text {re }}$ séance du 28 novembre 1930, S. 3642 f. und Ebenda, $1^{\text {re }}$ séance du 4 décembre 1930, S. 3727-3731). 
wirtschaftlicher Strukturreformen zu und richtete Kritik in erster Linie gegen den vorgeschlagenen Finanzierungsmodus. Während man seit Ende 1929 deshalb die Aufnahme neuer Staatsanleihen als effektivere und einträglichere Lösung verteidigt hatte, ging man im Juni 1930 in die Offensive, stellte das Vorhandensein der nötigen staatlichen Mittel grundsätzlich in Frage und forderte eine anleihengestützte Ausweitung des Programms. ${ }^{26}$ So hatte sich der Finanzminister in allererster Linie mit der Klarstellung der finanzpolitischen Grundlagen der Regierungspolitik zu beschäftigten. Das Prinzip des Budgetgleichgewichts und die Möglichkeit seiner Aufrechterhaltung ohne neue Staatsverschuldung nahmen in Reynauds Argumentation den zentralen Platz ein.

Die finanzpolitische Orthodoxie Reynauds in diesem Punkt entsprach der Haltung Tardieus und dominierte in allen seinen Äußerungen des Jahres 1930: Wie sein Ministerpräsident lehnte Reynaud den Rückgriff auf neue Anleihen oder die bewußte Inkaufnahme eines Budgetdefizits strikt ab und favorisierte statt dessen die kontinuierliche Amortisierung der aufgelaufenen Staatsschuld. ${ }^{77}$ Damit vertrat er ein Prinzip der traditionellen Finanzlehre, das mit der Großen Krise und der daraus erwachsenen Neuorientierung der Finanzwissenschaft um Keynes im angloamerikanischen Raum bald in Frage gestellt, in Frankreich jedoch auf Kabinettsebene, unter der traditionalistisch orientierten Beamtenschaft des Finanzministeriums, in der Leitung der „Banque de France“ und in der einflußreichen Wirtschaftspresse noch lange darüber hinaus als Kristallisationspunkt „vernünftiger" Finanzpolitik und favorisiertes Präventivmittel zur Krisenabwehr fortbestand. ${ }^{28}$ De facto bereits ab dem Haushaltsjahr 1930/31 zunehmend ausgehöhlt und nurmehr auf dem Papier parlamentarisch verabschiedeter Haushaltspläne existierend ${ }^{29}$, erlitten dieses Prinzip und die damit verbundene Deflationspolitik diverser rechter Regierungen im Mai 1935 ihren entscheidenden Rückschlag: Erstmals seit 1926 war der regelmäßige Rückgriff auf Vorschüsse seitens der Bank von Frankreich zum Zwecke des Budgetausgleichs nicht mehr zu umgehen. ${ }^{30}$ Das Beharrungsvermögen der Doktrin des ausgeglichenen Staatshaushalts lag wesentlich in Faktoren begründet, die über rein wirtschaftliche Erwägungen hinaus in den Bereich des Psychologischen und der politischen Traditionsbildung reichten. Im Verständnis jener bürgerlichen politischen Führungsschicht, die seit 1928 die parlamentarische Mehrheit stellte, konnte es keinem Zweifel unterliegen, daß Inflation und Währungsverluste der frühen zwanziger Jahre ihren Ausgang in Budgetdefiziten und wirtschaftspolitischen Fehlentscheidungen genommen hatten. Wenig strittig war auch, daß es schließlich die straffe Stabilisierungspolitik Poincarés

26 Vgl. dazu die im Umfeld Tardieus entstandene Analyse des Verhaltens der Opposition „Le financement de l'outillage national. Projet de note de la Présidence du Conseil“, 30.6. 1930 (Archives économiques et financières (künftig: AEF), B 33180).

27 Zur Haltung Tardieus: Monnet, Refaire la République, S. 144.

28 Vgl. hierzu stellvertretend für eine unübersehbare Zahl gleichgestimmter Äußerungen eine Note aus dem Finanzministerium vom Mai 1932: „If a strong effort is made to balance the budget, from the start of the new legislature, the Treasury will be preserved from the grave difficulties that are being experienced by almost all the nations abroad as a result of the crisis." (Note vom 12.5. 1932; AEF, B 33190, zitiert nach der englischen Übersetzung in Mouré, Managing, S. 161).

29 Zum Verhältnis von parlamentarisch verabschiedeten und tatsächlichen Budgets seit $1919 \mathrm{vgl}$. die Tabellen bei Sauvy, Histoire économique I, S. 367-369.

30 Im Überblick: Mouré, Managing, S. 156-190 und 274-280. 
gewesen war, die mit dem Budgetgleichgewicht den Wohlstand zurückgebracht hatte. ${ }^{31}$ Ungeachtet der persönlichen wirtschafts- und finanztheoretischen Überzeugungen der maßgeblichen Politiker stellte deshalb die Aufrechterhaltung zumindest des äußeren Anscheins einer soliden Gleichgewichtspolitik einen finanzpolitischen Imperativ für jeden bürgerlichen Minister dar, der gewillt war, das Erbe Poincarés für das eigene Handeln nutzbar zu machen.

Nicht zufällig bestimmten darum oberhalb aller technischen Details zwei argumentative Fixpunkte Reynauds öffentliche Rechtfertigung seiner Finanzpolitik. Gegen alle Einwendungen der Opposition machte er zum einen regelmäßig den Anspruch auf legitime Nachfolge und kompetente Fortführung der „expérience Poincaré“ geltend, instrumentalisierte deren Erfolgsgeschichte: „Tout permet d'espérer que nous entrons dans une grande période de notre histoire. Comment ne pas rendre justice, en tout cas, au redressement merveilleux que la France vient d'accomplir!" Der verzögerte Einbruch der Weltwirtschaftskrise in Frankreich gab ihm zum anderen genug Anlaß, an der Effektivität der einmal eingeschlagenen Strategie des Budgetausgleichs auch im Hinblick auf die nun zu leistende Abschirmung der französischen Wirtschaft gegen die im Umkreis grassierende Weltwirtschaftskrise nicht zu zweifeln. ${ }^{32}$

Im Endergebnis konnte die Regierung Tardieu keine der beiden Vorgaben einlösen: Weder gelang es, den Staatshaushalt in der Nachfolge des großen Leitbilds erneut zu stabilisieren, noch konnte die Krise dauerhaft ferngehalten werden. Daß ersteres nicht erreicht wurde, ging nicht zuletzt zurück auf eine auch allgemein politisch motivierte Steuer- und Ausgabenpolitik, die angesichts der heraufziehenden Depression ihr konjunktursteigerndes Ziel verfehlte und in der Endabrechnung entscheidend dazu beitrug, das angestrebte Budgetgleichgewicht $\mathrm{zu}$ kompromittieren. Wenn letzteres mißlang, dann sicherlich stärker noch aufgrund exogener Faktoren, deren langdauernde Unterschätzung jedoch unter Tardieu ihren Anfang nahm.

\section{b) Interferenzen von politischer Doktrin und finanzpolitischem Handeln: die Politik der "dégrèvements“}

Als Erbe aus der Zeit wirtschaftlicher Prosperität zwischen 1926 und 1929 hatte die erste Regierung Tardieu nicht nur bedeutende Budgetreserven übernommen, sondern daneben auch die unabweisbare Verpflichtung, einer Steuerdiskussion Rechnung zu tragen, die noch unter Poincaré im Verlauf des Jahres 1929 zu ersten Ansätzen einer Fiskalreform zugunsten von Familien oder Geringerverdienenden sowie zur Entlastung von Grundnahrungsmitteln und Wertpapiervermögen geführt hatte. ${ }^{33}$ Die unvorsichtige "Enthüllung“ Chérons vom November 1929, über einen Bestand von 17,5 Milliarden Francs Budgetüberschuß zu verfügen ein Betrag, der der Hälfte des Staatshaushalts entsprach -, tat das ihre, um in Presse und parlamentarischer Opposition eine heftige Kampagne gegen „Überbe-

31 Zur prägenden Kraft des Poincaréschen Vorbilds: Ebenda, S. 156.

32 So etwa in seiner großen finanzpolitischen Rede im ostfranzösischen Epinal am 3. August 1930 (AN, 74 AP 13; abgedruckt in Le Temps, 4. 8. 1930, hier auch die Zitatc).

33 Sauvy, Histoire économique I, S. 386. 
steuerung “ und gegen das „Horten“ von Einnahmeüberschüssen zu entfachen, die ihre Wirkung nicht verfehlte. Blieben die Steuererleichterungen unter dem vorsichtigen Chéron noch begrenzt, so leitete sein Nachfolger Reynaud eine Phase „massiver" Steuersenkungen ein. Gemessen an den Plänen seines Vorgängers akzeptierte Reynaud 2,9 Milliarden Francs an zusätzlichen Entlastungen, damit an Einnahmeverlusten und setzte so den von Tardieu gewünschten klaren Kontrapunkt zur Politik Chérons. ${ }^{34}$ Insgesamt waren somit zwischen Juli 1929 und April 1930 5,6 Milliarden Francs an Steuernachlässen gewährt worden, was einer Verminderung der Steuerlast um über 10\% entsprach. ${ }^{35}$ Ein Schwerpunkt zeichnete sich freilich klar ab: Die Maßnahmen Reynauds berücksichtigten in erster Linie den Produktionsbereich, den Handel sowie die Finanzmärkte, deren Aktivität gefördert werden sollte. Von den am 26. April 1930 in der Kammer verabschiedeten 1,9 Milliarden Francs kam der Hauptanteil von 1,1 Milliarden der Senkung der Abgaben auf in- und ausländische Wertpapiere sowie auf Börsengeschäfte zugute; daneben wurde insbesondere die Grundsteuer von 18 auf $16 \%$ gesenkt, die $\mathrm{Lu}$ xussteuer vermindert und die Umsatzsteuer auf den Verkauf von Grundnahrungsmitteln reduziert. ${ }^{36}$

Widerspruch seitens der Linken konnte angesichts dieser unternehmer- und kapitalfreundlichen Politik nicht ausbleiben. Léon Blum formulierte ihn unter Verweis auf das sozialistische Gegenmodell, das die Favorisierung direkter Steuern, die Belastung hoher Einkommen und des Kapitalbesitzes, die Entlastung der Arbeitenden und der Konsumenten vorsah. ${ }^{37}$ Wenn auch seine apodiktische Einschätzung als „dégrèvements 'de classe' de $\mathrm{M}$. Paul Reynaud“38 überspitzt und allzu populistisch eingefärbt anmutet, so ist doch zweierlei nicht von der $\mathrm{Hand}$ zu weisen: In Abstimmung mit seinem Ministerpräsidenten inaugurierte Reynaud eine Finanzpolitik, die der Stärkung der Produktivkräfte im Interesse einer indirekt wirksamen Hebung des gesamtgesellschaftlichen Wohlstands den Vorrang einräumte vor direkt ansetzenden, sozial motivierten Lastenerleichterungen. Zwangsläufig ging damit eine Bevorzugung der Besitzenden einher ${ }^{39}$, die sich trefflich auch den allgemein politischen Zielen Tardieus dienstbar machen ließ. So war es wohl kein Zufall, daß die Hauptnutznießer der Steuerreform - Wertpapierinhaber, grundbesitzendes Bürgertum und Bauern - gerade jener mittelständischen und agrarischen Klientel entstammten, die die wichtigste Wählerschicht der Radikalsozialisten darstellten. Tardieus zentrales parteipolitisches Anliegen, mindestens den rechten Flügel der Radicaux zur Zusammenarbeit mit den modérés und zur endgültigen Abkehr von der langen linksliberalen Tradition einer „Union des Gauches" zu bewegen, war hier bestimmend. Die anvisierten Strukturrefor-

34 Monnet, Refaire la République, S. 145-147 (Zitat: S. 147); Sauvy, Histoire économique I, S. 386 f. spricht für die beiden verabschiedeten Finanzgesetze vom 16. und vom 26 . April 1930 von 2,65 Milliarden Francs an vorgesehenen Erleichterungen, Jackson erwähnt für das Jahr 1930 pauschal 6 Mrd. Francs an Steuernachlässen (Jackson, Politics of Depression, S. 26).

35 Monnet, Refaire la République, S. 146.

36 Vgl. zu den Zahlenangaben Sauvy, Histoire économique I, S. 386 f.; Bonnefous, Histoire politique V,S. 27.

37 Léon Blum, „Budget de classe. Dégrèvement de classe“, in: Le Populaire, 20. 4. 1930.

38 Ebenda.

39 Sauvy, Histoire économique I, S. 387. 
men selbst hatten bereits wesentliche Punkte des radikalsozialistischen Wirtschaftsprogramms aufgenommen, wie es der letzte Parteikongreß von Reims im Oktober 1929 vorgelegt hatte. Die Frage der Steuerreform bot wie erstere die Chance, erneut Anreize zur Annäherung zu setzen und im Falle des Mißlingens zumindest Einbrüche in die radikalsozialistische Wählerschaft zu erlauben. ${ }^{40}$

Die Kosten und die resultierenden finanzpolitischen Folgen der so eingegangenen Verpflichtungen erwiesen sich freilich als dauerhafter als die Regierung Tardieu und wirkmächtiger auch als die vergeblich ins Auge gefaßten koalitionspolitischen Kombinationen. Wohlgemerkt, der Charakter der bislang analysierten wirtschaftlichen Maßnahmen als Elemente eines umfassend angelegten und nach bestem Gewissen initiierten Stabilisierungs- und Erneuerungsprojekts steht ganz außer Zweifel - und selbst ein scharfer Kritiker der Regierungspolitik wie Léon Blum war bereit, dies anzuerkennen. ${ }^{41}$ Ebenso unbestreitbar allerdings ist auch, daß gerade der Anspruch Tardieus, aus letztlich politischen Gründen Strukturerneuerung, Amortisierung der Staatsschuld und Steuererleichterung gleichzeitig ins Werk zu setzen, die Rückkehr zum Budgetdefizit entscheidend beförderte. Die während des Haushaltsjahres 1929/30 zusätzlich verabschiedeten Ausgaben etwa zur Finanzierung des neuen Sozialversicherungsgesetzes ${ }^{42}$, von Soldatenpensionen und von interventionistischen Maßnahmen zum Schutz des Agrarsektors ließen die Ausgabenseite auf 55,7 Milliarden Francs anwachsen, während sie noch 1926 knapp 42 Milliarden umfaßt hatte. Trotz der noch 1930 über den Erwartungen liegenden Steuereinnahmen resultierte daraus für das Haushaltsjahr 1930/31 ein Defizit von über 4,9 Milliarden Francs. Bereits für den Folgehaushalt 1931/32 konnte der Verzicht auf neue Steuern und auf staatliche Anleihen bei gleichzeitiger rein theoretischer Minderung der Ausgaben nur über einen noch unter der Ägide Reynauds in die Budgetdiskussion eingebrachten finanztechnischen Trick erreicht werden. Das schließlich gewählte Verfahren zur Schönung der Staatsbilanz bestand darin, der "Caisse autonome d'amortissement", die 1926 unter Poincaré zur Rückzahlung der als Folgelast der Kosten des Ersten Weltkriegs auf-

40 Entsprechend schätzt Monnet, Refaire la République, S. 149-151 Tardieus Verhältnis zu den Radicaux und zur agrarischen Welt ein. Obwohl die Radikalsozialisten auch den Eintritt in die zweite Regierung Tardieu verweigert hatten, reichten Kontaktversuche zwischen dem Ministerpräsidenten und einer bedeutenden Strömung in der Partei, die einer "coalition de concentration “ aufgeschlossen gegenüberstand, bis in die Jahresmitte 1930; vgl. dazu Berstein, Parti radical II, S. 154157 und 160-164.

41 So geschehen in seiner Kammerrede zu den Steuererleichterungen für Börsentransaktionen und Aktienbesitz am 25. April 1930 unter Bezugnahme auf seine enttäuschten Vorstellungen über die Verwendung von Mitteln aus dem Youngplan: „Vous avez procédé autrement. Si vous l'avez fait, c'est que vous étiez convaincus que vous agissiez pour le bien général." (JO, Chambre des Députés, Débats parlementaires, 2e Séance du 25 avril 1930, S. 2235-2238, hier: S. 2237).

42 Das Gesetz vom 30. April 1930 beendete eine jahrzehntelange parlamentarische Diskussion über den Ausbau des französischen Sozialversicherungswesens und legte unter anderem den obligatorischen Eintritt all jener in Industrie, Handel und Landwirtschaft Tätigen in eine Krankenversicherung fest, die eine bestimmte Einkommensgrenze unterschritten; vgl. dazu: Henri Hatzfeld, Du paupérisme à la sécurité sociale 1850-1940. Essai sur les origines de la Sécurité sociale en France, Nancy 1989, S. 142-154; im Überblick auch: Heinz-Gerhard Haupt, Sozialgeschichte Frankreichs seit 1789, Frankfurt am Main 1989, S. 271-282; Walter Korpi, Un Etat-Providence contesté et fragmenté. Le développement de la citoyenneté sociale en France. Comparaisons avec la Belgique, l'Allemagne, l'Italie et la Suède, in: Revue française de science politique 45 (1995), S. 632-667, bes. S. 642 . 
gelaufenen „schwebenden Staatsschuld“ („dette flottante“) gegründet worden war, die Sorge für die Regelung von 1,9 Milliarden Francs staatlicher Verbindlichkeiten zu übertragen. Dadurch verschwand dieser Betrag aus der offiziellen Haushaltsbilanz, und zusätzliche Ausgabensteigerungen konnten formal folgenlos eingearbeitet werden. Tatsächlich belief sich das Defizit dieses Budgetjahrs dann aufgrund der übernommenen Folgelasten unter anderem aus dem „Plan Tardieu“, aus gesteigerten Militärausgaben sowie aufgrund neuer, krisenbedingter Ausgabenzuwächse auf über 5,4 Milliarden Francs. ${ }^{43}$

Dieses zweifelhafte Ergebnis einer unter vielversprechenden Vorzeichen begonnenen Finanzpolitik steht natürlich in eklatantem Gegensatz zu der ostentativen Hartnäckigkeit, mit der Tardieu wie Reynaud die Prinzipien orthodoxer Haushaltsführung und insbesondere den Erhalt des Budgetgleichgewichts für ihre Arbeit in Anspruch nahmen und regelmäßig als politische Waffe gegen die sozialistische Opposition einsetzten. Zwar wäre es zweifellos verfehlt, die entstandene Haushaltslage ausschließlich auf das Konto verfehlter Regierungspolitik zu schreiben. Das verbietet sich schon angesichts der Begehrlichkeiten, die eine Folge von positiv abgeschlossenen Finanzjahren zwangsläufig in den Reihen von Parlamentariern und Interessengruppen erweckt hatte. Auch die verzögerte Rezeption der heraufziehenden Krise beim politischen Personal Frankreichs insgesamt kann als entlastendes Argument angeführt werden. An sachverständigen Warnungen jedoch aus der Ministerialbürokratie hatte es nicht gefehlt, und Unkenntnis der drohenden Gefahr war es nicht, die für die Intransigenz Tardieus und Reynauds verantwortlich war.

Die erste einführende Übersicht bereits, die Reynauds Kabinettsdirektor im März 1930 seinem neuen Minister zur Lage der Staatsfinanzen unterbreitete, faßte unter Berücksichtigung der für die Durchführung des "Programme d'outillage“ nötigen Mittel ein Defizit von $2 \frac{1}{2}$ bis 3 Milliarden Francs ins Auge. ${ }^{44}$ Mitte April, kurz vor der Verabschiedung der Gesetze zur Sozialversicherungs- und Steuerreform, erachtete man in der "Direction du Mouvement des Fonds“ des Finanzministeriums die Gesamtheit des verfügbaren Staatsguthabens als verplant und sagte bei einem gegenwärtigen Defizit von 50 Millionen Francs den baldigen Rückgriff auf Anleihen zur Finanzierung der Staatsausgaben voraus. ${ }^{45}$ Wenige Monate später sah man sich genötigt, zur Deckung der laufenden und der bis 30. Juni 1931 anstehenden Ausgaben die Konvertierung eines Teils des französischen Devisenbestands anzuregen und unter anderem die Einstellung der weiteren staatlichen Finanzierung eines Programms zum sozialen Wohnungsbau vorzuschlagen - und

43 Vgl. Jackson, Politics of Depression, S. 231, Anm. 28; Bonnefous, Histoire politique V, S. 45. Zu den angegebenen Budgetdaten und deren Interpretation: Mouré, Managing, S. 158; Jackson, Politics of Depression, S. 26 f.; Margairaz, L'Etat, les finances et l'économie I, S. 37-39; zur Deutung der Politik Tardieus: Monnet, Refaire la République, S. 148.

44 „Ministère des Finances. Direction du Mouvement général des Fonds. No. 519/50. Note pour le ministre. Situation de la trésorerie“, 3. 3. 1930 (AEF, B 33180). Dagegen Mouré, Managing, S. 160, der ohne Benutzung archivalischer Quellen davon ausgeht, im Frühjahr 1930 habe im Finanzministerium keine Sorge angesichts steigender Ausgaben bestanden.

45 „Note sur la situation de la Trésorerie“, 17. 4. 1930 (AEF, B 33180). 
dies noch unter der Annahme, daß für Tardieus Strukturprogramm bis Mitte 1931 nur geringfügige Leistungen aufzubringen sein würden.46

Reynaud hatte die Warnzeichen durchaus nicht ignoriert. In der erweiterten und inhaltlich verschärften Fassung der ersten an ihn gerichteten Note, die er kurz nach Erhalt an seinen Ministerpräsidenten weitergegeben hatte, hatte sich der Finanzminister nicht nur die Warnungen der Administration zu eigen gemacht, sondern darüber hinaus eine eindringliche Mahnung zur soliden Finanzierung des "Outillage“-Projekts formuliert. Etwaigen Illusionen über vorhandene Haushaltsüberschüsse entzog er in ernüchternder Deutlichkeit und auf lange Frist die Grundlage: „En définitive, il apparaît que les disponibilités de la Trésorerie qui ont pu parfois sembler excessives, se trouvent, en réalité, inférieures aux charges qui pèseront durant les prochaines années sur la Trésorerie de l'Etat." ${ }^{47}$ Die baldige Wiederaufnahme der Praxis mittelfristiger Anleihen zur Finanzierung des Budgetdefizits schien Reynaud zu Beginn seiner Amtszeit praktisch unvermeidbar: „Il convient donc de prévoir, dans un avenir peu éloigné, le recours à l'émission de Bons du Trésor, qui était d'ailleurs d'usage constant avant la guerre." 48

Beide intern gewonnenen Erkenntnisse über den Zustand der Staatsfinanzen allerdings änderten in der Folge nichts an Reynauds loyaler Verteidigung der Regierungsprojekte. Als sich der Vorsitzende der Finanzkommission der Kammer, de Chappedelaine, Mitte Juni Auskunft über die verfügbaren Gelder für das Tardieusche Strukturprogramm erbat, wurde ihm seitens des Finanzministers die Auskunft zuteil, daß dafür unter der Voraussetzung eines ausgeglichenen Budgets etwa 5,465 bzw. 5,098 Milliarden Francs zur Verfügung ständen. ${ }^{49}$ Die hier aufgemachte Rechnung berücksichtigte jedoch ausdrücklich nicht den Bedarf des Fiskus in seiner Rolle als „Banquier du Budget“, wofür gewöhnlich eine Summe in Höhe von mehreren Milliarden zugrundegelegt wurde. 50 Zur Deckung dieses Bedarfs baute Reynaud im Eventualfall auf die Ausgabe von Schatzanleihen. ${ }^{51}$

Nurmehr durch geschickte Verlagerungen innerhalb des Haushalts und durch die bewußte Inkaufnahme mittelfristig wirksamer Neuverschuldung also bereits im Mai 1930 konnte der Anspruch aufrechterhalten werden, das ehrgeizige Programm alleine aus Haushaltsmitteln zu finanzieren. Allzu verführerisch war es offenbar, Fortschritte zu bieten, ohne neue Belastungen auferlegen zu müssen. Ob-

46 "Note pour le ministre“, 11. 9. 1930; vgl. auch „Note sur l'évolution probable de la situation de la Trésorerie au cours de l'année à venir", 25. 8. 1930 (AEF, B 33180).

47 „Note sur la situation de la Trésorerie, Remise à M. Tardieu“, 16. 3. 1930. (Ebenda).

48 Ebenda.

49 Reynaud an de Chappedelaine, Président de la Commission des Finances, 13.6. 1930; „Note sur les disponibilités de la Trésorerie, leur utilisation probable et la somme qui pourrait être affectée au financement du plan d'outillage national“", 27. 5. 1930 (AEF, B 33180). Das Schreiben bestätigte die Angaben, die der Finanzminister in einer Anhörung vor der Finanzkommission bereits am 2. Juni gemacht hatte; vgl. Commission des Finances, Procès-verbal de la séance du 2 juin 1930 (Archives de l'Assemblée Nationale).

50 Als „Banquier du Budget“ bezeichnete man die zentrale Aufgabe des Fiskus, für das Gleichgewicht zwischen laufenden Einnahmen und den anstehenden Ausgaben zu sorgen, die naturgemäß nicht exakt korrespondierten, insbesondere nicht in den ersten Monaten des Finanzjahres, wenn der Ausgabenbereich durch die Steuereinnahmen noch nicht gedeckt war; vgl. hierzu die Erläuterungen in „Note pour le ministre. Situation de la trésorerie“, 3.3.1930 (AEF, B 33180).

31 "Note sur les disponibilités de la Trésorerie, leur utilisation probable et la somme qui pourrait être affectée au financement du plan d'outillage national“, 27.5. 1930 (AEF, B 33180). 
wohl die beginnenden Krisensymptome im Staatshaushalt bereits ihre Spuren hinterlassen hatten, behielt der politische Wille gegenüber den finanzpolitischen Erfordernissen die Oberhand. Am Ursprung des Auseinanderklaffens von finanzpolitischer Prosperitätsdoktrin und faktisch längst eingeleiteter Wende zu den chronischen Budgetproblemen der dreißiger Jahre stand die billigende Inkaufnahme einer Ausgabenpolitik, die das Leistungsvermögen des Staatshaushalts überforderte. Die finanztechnischen Verfahrensweisen, mit denen es der Regierung Tardieu gelang, die Stunde der Wahrheit hinauszuzögern - wie gesehen, griff man zur Beibehaltung des Gleichgewichts unter anderem auf die Ausgliederung von Lasten aus dem ordentlichen Haushalt für 1931/32 zurück -, stellten darum weniger eine „ingeniöse Lösung “ 52 denn das Eingeständnis einer Niederlage dar, die langfristige Folgen zeitigen sollte.

Man mag einwenden, daß Tardieus prosperitätsorientierte Finanzpolitik unfreiwillig und gewissermaßen durch eine „List der Geschichte“ jenes „deficit spending " einleitete, das letztlich ein adäquates Mittel zur Eindämmung der Großen Krise hätte darstellen können. ${ }^{53}$ Aber abgesehen davon, daß der offensichtliche Ursprung des neuen Defizits in der unvorsichtigen Ausgabenpolitik Tardieus gerade die Fixierung nachfolgender Regierungen auf deflatorischem Vorgehen anstatt auf einer antizyklischen Investitionspolitik begünstigte ${ }^{54}$, blieb auch darüber hinaus die Krisenlösungskapazität liberaler Finanzpolitik Tardieuscher und Reynaudscher Prägung eher beschränkt.

\section{c) Liberale Finanzpolitik und heraufziehende Weltwirtschaftskrise}

In der politischen Führung Frankreichs reagierte man aufgrund des im internationalen Vergleich eher schleichenden Auftretens der Weltwirtschaftskrise im eigenen Land nur mit Verzögerung, und Paul Reynaud nahm hier keine Ausnahmestellung ein. ${ }^{55}$ Ebensowenig wie bei Tardieu läßt sich in seinem finanzpolitischen Handeln der Wille zur Modifizierung einmal vertretener Konzepte unter dem Aspekt der konsequenten Kriseneindämmung feststellen.

Früher freilich als die große Mehrzahl seiner Landsleute zeigte sich Reynaud, der noch im September 1929 die USA bereist hatte, vom ungewöhnlichen Ausmaß der Depression überzeugt. Bezeichnend genug für die in Frankreich zu Anfang des Jahres 1930 vorherrschende Beurteilung, provozierte der neue Finanzminister heftige Proteste in Finanzkreisen und Presse, als er die fallenden Preise auf dem Pariser Aktienmarkt im März als Auswirkungen einer „enormen Wirtschaftskrise" charakterisierte, der gegenüber "nichts unvorsichtiger" sei, als die Hoffnung auf „rasche Erholung“. 56 Der Vorwurf des geschäftsschädigenden Pessimis-

52 So Bonnefous, Histoire politique V, S. 45.

53 J.-J. Carré/P. Dubois/E. Malinvaud, French Economic Growth, Stanford 1975, S. 381; Mouré, Managing, S. 19.

54 Mouré, Managing, S. 189.

55 Vgl. seine diesbezüglichen Ausführungen in: Reynaud, Mémoires I, S. 292-298.

56 Die gegenüber dem Chefredakteur von L'Echo de Paris, Marcel Hutin, gemachten Äußerungen gelangten aufgrund einer Indiskretion in Form eines Artikels an die Öffentlichkeit; vgl. L'Echo de Paris, 8. 3. 1930. Dazu auch: Reynaud, Mémoires I, S. 292-294. Zur Resonanz der Äußerungen 
mus, der gegen Reynaud laut wurde ${ }^{57}$, war typisch für die weithin etablierte Denkart und Sprachregelung, wonach eine außerhalb Frankreichs entstandene und in der verfehlten Kreditpolitik der USA und Großbritanniens wurzelnde Überproduktionskrise mit den klassischen Mitteln der Rezessionsabwehr effektiv zu bekämpfen sei: falls sie Frankreich je erreiche, was unter anderem dadurch vermieden werden könne, daß man sie nicht durch allzugroße Aufmerksamkeit und öffentliche Diskussion „herbeirede“. .58

Ungerechtfertigt war der Vorwurf des ökonomischen Defätismus gegen Reynaud indes allemal, denn aus seiner Bereitschaft zur frühzeitigen Wahrnehmung der Krise resultierte keineswegs eine Lösungsstrategie, die sich von der allgemein akzeptierten Anschauung wesentlich unterschied. Auch zur Krisenabwehr setzte er in Übereinstimmung mit Tardieu in erster Linie auf eine orthodoxe Politik des Budgetgleichgewichts und damit auf eine Doktrin, die bis 1935/36 in der Öffentlichkeit und auf Regierungsebene den dominierenden Platz einnahm: „Une crise, immense par son étendue, sévit sur le monde. L'économie française est de beaucoup celle qui a le mieux résisté à ses effets" 59 ; „il est vrai [...] que la crise économique atteint de jour en jour des zones jusque-là épargnées. Forte raison pour être prudents, pour ne pas mettre en péril l'équilibre budgétaire en nous lançant dans une politique d'emprunt." 60

Optimistisch ging auch er davon aus, daß die finanzielle und monetäre Basis der französischen Wirtschaft genügend stark entwickelt sei, um deren dauerhafte Resistenz zu begründen. Unter Verweis auf die seit 1926 auf das Doppelte angewachsenen Goldreserven der Bank von Frankreich, die Verminderung der Staatsschuld im gleichen Zeitraum und die Stärke des französischen Kredits im europäischen Vergleich gab er sich paradoxerweise überzeugt, daß die einzige Gefahr am Horizont gerade aus der weitgehenden Verschonung durch die Krise resultieren könnte: „Le danger pour nous n'est donc pas pour l'avenir d'ordre monétaire, ni d'ordre financier, si les finances publiques sont sagement gérées et si les budgets restent en strict équilibre. Le danger serait plutôt [...] un danger d'ordre économique, en ce sens que les pays qui ont le plus souffert de la crise sont ceux qui se sont le plus profondément réformés et qui, ainsi, seront les mieux placés au jour de la reprise des affaires pour la lutte sur les marchés mondiaux." 61

Maßnahmen der Regierung Tardieu zur Immunisierung der heimischen Wirtschaft blieben im wesentlichen auf das traditionelle finanzpolitische Feld be-

Reynauds in Politik und Finanzwelt siehe auch eine Note der „Sûreté“: „A.2414. A.S. des déclarations de M. Paul Reynaud“, 10.3.1930 (AN, F712957).

57 Vgl. etwa Le Figaro, 9. 3. 1930; L'Action Française, 10. 3. 1930.

58 Zur frühen Rezeption der Weltwirtschaftskrise in Frankreich: Mouré, Managing, S. 27-45, hier bes.: S. 27-29; Jackson, Politics of Depression, S. 27-34; Ralph Schor, Une étude d'opinion: la droite française face à la crise mondiale de 1929, in: L'Information historique 1 (1974), S. 23-28 und 2 (1974), S. 64-70.

59 Rede Paul Reynauds in Epinal, 3. 8. 1930 (AN, 74 AP 13; Le Temps, 4. 8. 1930).

60 JO, Chambre des Députés, Débats parlementaires, Séance du 27 novembre 1930, S. 3598.

61 JO, Chambre des Députés, Débats parlementaires, 1re séance du 4 décembre 1930, S. 3727.

Clague, Vision and Myopia, S. 111 überschätzt den „erzieherischen“ Einfluß Reynauds in bezug auf die Krisenbewertung durch Tardieu: Beider Optimismus, Frankreich die Depression durch entsprechende Schutzmaßnahmen weitgehend unbeschadet überstehen zu lassen, unterschied sich nach ihren öffentlichen Äußerungen nicht. 
grenzt, und auch der „Plan d'outillage national“ bildete entgegen anderslautenden rückblickenden Behauptungen Tardieus keineswegs ein bewußt eingesetztes Palliativ zur Krisenabwehr. ${ }^{62}$ Deklariert als Element einer wohlstandsorientierten Politik, war der beschäftigungsfördernde Beieffekt des Programms zwar erwünscht, doch gibt es keine Anhaltspunkte dafür, daß Tardieu oder sein Finanzminister willentlich eine Politik des "deficit spending“ etwa nach dem Vorbild Roosevelts einleiteten. ${ }^{63}$ Für beide Politiker endete die Bereitschaft zur forcierten Ausgabenpolitik da, wo die Grenze eines zumindest dem Anspruch nach beibehaltenen Budgetgleichgewichts öffentlich sichtbar überschritten worden wäre. ${ }^{64}$ So distanzierte sich Tardieu unmißverständlich von der „neuen Doktrin der Prosperität durch Budgetungleichgewicht ${ }^{\text {}} 65$, und Reynaud verteidigte den bescheideneren Umfang des „Outillage“-Projekts der Regierung gegen ein weitaus ambitiöseres, anleihefinanziertes Vorhaben der Opposition hartnäckig gerade unter Verweis auf die so noch mögliche Deckung durch Haushaltsmittel.66 Ebenso wie das bewußte "deficit financing" rangierte aber auch die theoretische Option einer Abwertung des Franc für Tardieu wie für Reynaud im Jahr 1930 außerhalb des Vorstellbaren. ${ }^{67}$

Uneinheitlich in sich, entzieht sich die Finanzpolitik Tardieus einer pauschalen Einordnung. Dabei gibt es keinen Grund zur Annahme, Reynaud hätte sich in irgendeinem Punkt im grundsätzlichen Gegensatz zu seinem Ministerpräsidenten befunden. Wo ein solcher etwa in bezug auf Prinzipien solider Haushaltsführung bestanden hatte, hatte sich der Politiker schließlich gebeugt und dazu beigetragen, den schönen Schein zu erhalten.

Elemente orthodoxer liberaler Finanzpolitik, die primär auf die Gesundung der Wirtschaft über die Steuerung von Preisen und Einkommen zielten, standen neben ersten Ansätzen gemäßigt staatsinterventionistischen Vorgehens etwa zum Schutz von Agrarinteressen. ${ }^{68}$ Die zukunftsweisende Ergänzung des finanzpolitischen Instrumentariums durch die Einführung eines „sous-secrétariat d'Etat de la présidence du Conseil, chargé de l'Economie nationale“, besetzt durch Reynauds Parteifreund André François-Poncet und unter anderem mit Koordinierungsaufgaben sowie der Betreuung des Strukturprogramms befaßt, kontrastierte mit der schlechten personellen Ausstattung und den kaum vorhandenen Kompetenzen des Organs; die Ausarbeitung der Grundlinien einer zusammenhängenden staatli-

62 So vertreten in: André Tardieu, Devant le pays, Paris 1932, S. 104-107.

63 Diese Darstellung eines vorausschauenden Tardieu bietet: Binion, Defeated Leaders, S. 308. Kritisch dagegen Clague, Vision and Myopia, S. 108-119; Saly, Grands travaux, S. 303-308; Jackson, Politics of depression, S. 23; offenbar ohne Kenntnis der Ausführungen Jacksons: Monnet, Refaire la République, S. $143 \mathrm{f}$.

${ }_{64}$ Für Tardieu: Clague, Vision and Myopia, S. 112.

65 André Tardieu, La Note de la Semaine, 1937, Paris 1938, S. 121; zitiert nach Clague, Vision and Myopia, S. 112; dort auch wcitere Belege.

66 Vgl. etwa seine Parlamentsrede vom 27.11. 1930 (JO, Chambre des Députés, Débats parlementaires, Séance du 27 novembre 1930, S. 3596 und passim).

67 Dies räumte Reynaud im Rückblick ein: Paul Reynaud, Au coeur de la mêlée 1930-1945, Paris 1951, S. $52 \mathrm{f}$

68 Margairaz, L'Etat, les finances et l'économie, S. 30-35; Belege für den interventionistischen Impetus der Regierung Tardieu auch bei Richard F. Kuisel, Capitalism and the state in modern France. Renovation and economic management in the twentieth century, Cambridge 1983, S. 90-92. 
chen Wirtschaftspolitik überstieg seine Leistungsfähigkeit bei weitem. ${ }^{69}$ Die Forcierung einer nicht zuletzt am amerikanischen Vorbild orientierten, auf Effektivität und rationale Nutzung der menschlichen und materiellen Ressourcen des Landes setzenden Reformpolitik stand neben einem umfangreichen sozialpolitischen Werk, zu dem Tardieu freilich nach jahrelangen Beratungen nur den Schlußstein setzte und zu dem er auch ein eher gespaltenes Verhältnis unterhielt.70

Als Adlatus Tardieus sammelte Reynaud in seinem ersten Ministeramt wichtige Erfahrungen auf finanztechnischem Gebiet, die er bei Antritt seiner Funktion noch nicht besessen hatte. ${ }^{71}$ Diese zunächst eingeschränkte fachliche Kompetenz und der Führungsstil seines Ministerpräsidenten, der auf außen- wie auf finanzpolitischem Gebiet die Zügel nicht aus der Hand gab, verwehrten Reynaud, entscheidende eigene Akzente zu setzen - ganz im Gegensatz zu seiner zweiten Amtszeit im gleichen Ressort ab 1938.

\section{Kolonialpolitik in Zeiten des Umbruchs 1931/32}

Nur ein Jahr - vom 27. Januar 1931 bis zum 16. Februar 1932 - amtierte Paul Reynaud in der Rue Oudinot. Zu kurz, um wirklich prägend zu wirken in einem Sachgebiet, in dem allein schon aufgrund der Komplexität der Materie und der räumlichen Ausdehnung des beteiligten Apparats von vorneherein nicht mit raschen Resultaten gerechnet werden konnte. Sein Spielraum im Kabinett war freilich ungleich größer als noch unter Tardieu: Der neue Regierungschef Pierre Laval interessierte sich kaum für die kolonialpolitische Materie und mischte sich in die Amtsführung seines Ministers nicht ein.72

Gleichwohl war Reynaud kein Kolonialminister vom Range eines Albert Sarraut oder Marius Moutet, beides Politiker, die entweder nach passioniertem Engagement in kolonialpolitischen Gremien oder aber versehen mit überseeischer Verwaltungserfahrung an ihr Amt herangingen. ${ }^{73}$ In Gegenwart erfahrener Praktiker erweckte Reynaud stets eher den Eindruck eines aufmerksam Lernenden, der die

69 Bis 1936 existierte in Frankreich kein Wirtschaftsministerium (Margairaz, L'Etat, les finances et l'économie, S. 35 f.); vgl. zur Bestellung François-Poncets auch die optimistischere Einschätzung des deutschen Botschafters: Hoesch an AA, 21.3. 1930 (PA-AA, R 70721). Zur Person FrançoisPoncets in deutscher Wahrnehmung auch die ausführliche „Aufzeichnung“ des Auswärtigen Amts vom 10. 7. 1931 (PA-AA, R 30207).

70 Rückblickend erklärte er, das Sozialversicherungsgesetz und den beschlossenen freien Unterricht in den Eingangsklassen des Gymnasiums in ihrer verabschiedeten Form nicht gutgeheißen zu haben (André Tardieu, La Révolution à refaire. Band 1: Le Souverain captif, Paris 1937, S. 15; dazu Jackson, Politics of Depression, S. 33).

71 Reynaud, Mémoires I, S. 290.

72 Ebenda, S. 299.

73 Albert Sarraut (1872-1962), eine der führenden Figuren der radikalsozialistischen Partei im französischen Südwesten, wo sein Bruder Maurice die einflußreiche „Dépêche du Midi“ leitete, bekleidete unter anderem zwischen 1920 und 1924 das Amt des Kolonialministers in mehreren Regierungen des „Bloc national“. Zwischen 1911 und 1914 bzw. 1916 und 1919 war er Generalgouverneur in Indochina gewesen und hatte sich seither den Ruf eines ausgewiesenen Experten in Kolonialangelegenheiten erworben.

Der Sozialist Marius Moutet (1876-1968), seit Ende des Ersten Weltkriegs engagierter Befürworter kolonialer Autonomietendenzen, amtierte zwischen Juni 1936 und April 1938 bzw. erneut zwischen Januar 1946 und Oktober 1947 mehrfach in der Rue Oudinot. 
fehlende Sachkenntnis durch ein um so intensiveres Informationsbedürfnis auszugleichen suchte. Im Haut Conseil Colonial, inmitten der Crème französischer Kolonialpolitiker und -beamter ${ }^{74}$, blieb er zurückhaltend, wurde oft erst dann aktiv, wenn Finanzprobleme oder Fragen von allgemeinerer politischer Bedeutung zur Sprache kamen.

Dennoch ist seine Amtsperiode aus mehreren Gründen von Interesse. Sie fiel in eine Epoche des Übergangs, in der das „Empire colonial“" Frankreichs in der "France métropolitaine" selbst wie auch an der Peripherie zunehmend unter ideologischen, politischen und militärischen Druck geriet. Kolonialer Mythos und problemschwangere Realität drohten zum erstenmal in systemgefährdender Weise auseinanderzufallen, eine Entwicklung, die die politische Klasse vor wachsende Integrationsprobleme stellte. Zwei extreme Manifestationen von Idealbild und Wirklichkeit - die große Pariser Kolonialausstellung von 1931 und die daneben anwachsenden gewaltsamen Unruhen in Indochina - bestimmten die kurze Amtszeit Reynauds. Deren Betrachtung wird deshalb nicht nur ein beliebiges Mosaikstück in ein Politikerprofil einfügen. Mit der Kolonialfrage gerät vielmehr ein Problemkreis in den Blick, der, anders als zur gleichen Zeit in Deutschland, eine die Nation bewegende Aktualität und Geschichte besaß. Liberales politisches Denken und Handeln hatte zu brisanten Fragen Stellung zu beziehen, die von grundlegenderer als außenpolitischer Relevanz waren. Jedem verantwortlichen Kolonialpolitiker war abverlangt, zumindest implizit Position zu nehmen zur zivilisatorischen „Mission“ Frankreichs in der Welt, zur Rechtfertigung einer erweiterten, "plus grande France" und zur damit verbundenen Problematik von Fortschritt und Modernisierung schlechthin.

Dem Neuling im Amt wurde diese Aufgabe freilich „erleichtert" durch einen festen ideologischen Traditionsbestand, einen weitreichenden prinzipiellen, wenn auch nicht unangefochtenen nationalen Konsens in der Kolonialfrage, der nurmehr im PCF auf programmatisch-grundlegenden Widerspruch stieß. Die Innovationsfreiheit eines jeden bürgerlichen Kolonialministers hatte dort ihre soliden Grenzen, wo sie diesen Konsens in Frage gestellt hätte. ${ }^{75}$ Anhand der

74 Der "Haut Conseil Colonial“ bildete seit der Reorganisation des "Conseil Supérieur des Colonies" im September 1920 das neue Herzstück dieses Expertengremiums, dem seit 1883 die Beratung von Parlament und Regierung in allen Kolonialfragen oblag. Im Gegensatz zu zwei weiteren Untersektionen, die sich mit ökonomischen und juristischen Angelegenheiten befaßten, behandelte der „Haut Conseil Colonial“ sämtliche allgemeinen Fragen bezüglich der Entwicklung und Verwaltung der Kolonien. Neben dem amtierenden Minister, der den Vorsitz führte, gehörten ihm die ehemaligen Kolonialminister und Generalgouverneure sowie Vertreter des Außen-, Kriegsund Marineressorts an (Stephen H. Roberts, The History of French Colonial Policy 1870-1925, London 1963, S. 137-144).

$75 \mathrm{Zu}$ Wurzeln, Form und Grenzen dieses Konsensus: Raoul Girardet, L'apothéose de la „plus grande France“. L'idée coloniale devant l'opinion française (1930-1935), in: Revue française de science politique 18 (1968), S. 1085-1114; eine ausführliche Version der hier entwickelten Thesen in: ders., L'idée coloniale en France de 1871-1962, Paris 1972; Henri Brunschwig, Mythes et réalités de l'impérialisme colonial français, 1871-1914, Paris 1960; Charles-Robert Ageron, France coloniale ou parti colonial?, Paris 1978. Daneben auch für die III. Republik von Interesse: D. Bruce Marshall, The French Colonial Myth and Constitution-Making in the Fourth Republic, New Haven/London 1973. Zum PCF: Jakob Moneta, Die Kolonialpolitik der französischen KP, Hannover 1968, bes. S. $11 \mathrm{ff}$.

Moderne Überblicksdarstellungen zur französischen Kolonialgeschichte der Zwischenkriegszeit existieren bislang erst in begrenzter Zahl: Jacques Thobie/Gilbert Meynier/Catherine Coquery- 
Selbstpositionierung Reynauds im Rahmen der „kolonialen Idee“ erschließen sich somit überpersönliche Prägungen und Elemente einer politischen Doktrin, die von der unlösbaren Verbindung Frankreichs mit seinen Kolonien ausging. Diese Vorstellung von einer übergreifenden Völkergemeinschaft, realisiert im Rahmen der französischen Nation und geeint durch gemeinsame politische, wirtschaftliche und kulturelle Interessen, gehörte bis in die zweite Nachkriegszeit zum intellektuellen Rüstzeug vieler französischer Politiker. ${ }^{76} \mathrm{Mehr}$ noch bleibt deshalb zu fragen, wie denn konkret das Verhältnis zwischen Kolonialdiskurs und gouvernementaler Praxis beschaffen war, einer Praxis zumal, die früher als in anderen Ressorts mit gravierenden Krisensymptomen konfrontiert war. In drei Schritten sollen ideologische, ökonomische und politische Aspekte französischer Kolonialpolitik der frühen dreißiger Jahre am biographischen Beispiel in den Blick genommen werden.

Noch als Finanzminister war Reynaud an der Vorbereitung der internationalen Pariser Kolonialausstellung beteiligt gewesen, deren konzeptionelle Ursprünge bis in die Vorkriegszeit zurückreichten. Unter enormem organisatorischen und materiellen Aufwand schließlich zwischen Mai und November 1931 in Szene gesetzt, bot sie über sechs Monate hinweg eine umfassende Selbstdarstellung der Kolonialmacht Frankreich. Auf über 100 Hektar Fläche war im Bois de Vincennes östlich von Paris eine exotische Märchenlandschaft eigenen Charakters entstanden. Sie sollte mit Informationen aller Art aufwarten, in erster Linie aber Neugier und Einbildungskraft ihrer Besucher zugunsten der kolonialen Sache mobilisieren. Neben dem angebotenen Studienmaterial, den Statistiken und Fachkongressen dominierte der Wille der Gestalter zur sinnlichen Präsentation. Die Pavillons der beteiligten Staaten waren in Form laotischer Pagoden, javanesischer Tempel oder afrikanischer Hüttenbauten gehalten, der Gastgeber bot als Hauptattraktion die Nachbildung des monumentalen Tempels von Angkor. Ein Programm szenischer Darstellungen, folkloristischer Tanzveranstaltungen, kunsthandwerklicher Ausstellungen und weiterer breitenwirksamer Vergnügungen rahmte das Ereignis ein. Das Konzept kam an: Bis Ende November 1931 hatten über 8 Millionen inund ausländische Besucher Eintrittskarten gelöst, angezogen nicht zuletzt durch den dauerhaft errichteten Zoo und ein Kolonialmuseum, befördert u.a. durch die rechtzeitig fertiggestellte Linie 8 der Pariser Métro. Jenseits aller Belustigungen verband sich freilich eine politisch-didaktische, bewußt mythenstiftende Funktion von Anfang an mit der Veranstaltung.77 Der verantwortliche Fachminister

Vidrovitch/Charles-Robert Ageron, Histoire de la France coloniale. Band II: 1914-1990, Paris 1990; Henri Blet, France d'outre-mer: l'oeuvre coloniale de la IIIe République, Grenoble 1950; Roberts, History of French colonial policy; Pierre Montagnon, La France coloniale. La gloire de l'Empire, Paris 1988. Vgl. deshalb daneben auch: Borne/Dubief, Crise des années 30, S. 60-72.

$76 \mathrm{Zu}$ dieser Definition vgl. Marshall, French Colonial Myth, S. $11 \mathrm{f}$.

77 Umfangreiches dokumentarisches Material zur Kolonialausstellung von 1931 findet sich gesammelt in der seit 1986 archivisch geordneten Serie "Exposition coloniale internationale (1931)“ im Centre des Archives d'Outre-mer, Aix-en-Provence (künftig: CAOM). Als gedruckte Materialsammlung dazu liegt der Rechenschaftsbericht des verantwortlichen Leiters vor: Exposition Coloniale Internationale 1931, Paris. Rapport général présenté par le gouverneur général Olivier, Rapporteur général, délégué général à l'Exposition. 7 Bände, Paris 1932-34. Dazu auch: Reynaud, Mémoires I, S. 299-335. 
Reynaud fügte sich bruchlos in den Traditionsrahmen ein, mehr noch, er aktivierte und instrumentalisierte ihn gegen die inneren und äußeren Gefährdungen des kolonialen Frankreich.

Die Eröffnungsrede, die Paul Reynaud am 6. Mai 1931 im Anschluß an die einführenden Worte von Staatspräsident Doumergue hielt, bot nichts weniger als eine Sammlung der wichtigsten Topoi des republikanischen Kolonialdiskurses. Die Berufung Frankreichs zur Erschließung außereuropäischer Gebiete im Namen einer „menschlichen, sanften und universellen Zivilisation“ lag für den Minister auf der Hand. Sie bedurfte keiner weiteren Begründung, reflektierte vielmehr einen Prozeß der natürlichen Angleichung unterschiedlicher Zivilisationsstufen aneinander: „Non, le fait colonial n'est pas mort. Il n'est pas arbitraire, il est aussi fatal qu'une loi physique car il tend à combler une différence de niveau entre deux civilisations contemporaines. Il y a une loi des vases communicants. On peut ennoblir ou avilir le fait de la colonisation, mais il est inutile de le justifier." 78 Die segensreichen Taten der französischen Ärzte, Lehrer, Soldaten und Siedler seien unübersehbar: Hygiene, Wissen, Sicherheit, Friede und Ordnung erwuchsen da, wo vorher Krankheit, Unwissenheit, Unterdrückung und Chaos herrschten, kurz: „Nous avons apporté la lumière dans les ténèbres“. Aus zwei Grundannahmen ergab sich also der moralische Wert des kolonialen Engagements: aus der Hierarchisierung der Zivilisationsformen und der Verknüpfung dieses Postulats mit teleologisch gerichtetem Fortschrittsdenken. Die eine und unteilbare französische Republik als Trägerin eines humanen, freiheitspendenden, überlegenen Ideals, das weitestmögliche Verbreitung zu finden hatte-eine solche Bezugnahme auf das Denken der Revolution gab in der Tat den Kern der „kolonialen Idee“ wieder, wie sie sich während des 19. Jahrhunderts nicht ohne Widerstände allmählich in den republikanischen Traditionsbestand eingefügt hatte. ${ }^{79}$

Mit dem Appell auf „mise en valeur de la France extérieure“, ebenfalls ein Schlüsselterminus, griff Reynaud dagegen auf eine jüngere „Sedimentschicht“ zurück. Gemeint war die Herstellung und Bewahrung einer engen, vor allem ökonomisch orientierten Interessengemeinschaft mit der „France d'outre-mer" zur Garantie der ökonomischen Unabhängigkeit Frankreichs. Jenseits des engeren Wortsinns erwies Reynaud damit zugleich indirekt dem Schöpfer dieses kolonialpolitischen Konzepts, Albert Sarraut, seine Referenz. Schon in den frühen zwanziger

Die obigen Ausführungen zur Kolonialausstellung beruhen daneben im wesentlichen auf den pertinenten Analysen bei: Catherine Coquery-Vidrovitch, La colonisation française 1931 - 1939, in: Thobie/Meynier/Coquery-Vidrovitch/Ageron, Histoire de la France coloniale II, S. 211-308, hier: S. 213-225; Charles-Robert Ageron, L'exposition coloniale de 1931. Mythe républicain ou mythe impérial?, in: Pierre Nora (Hg.), Les Lieux de mémoire. Band I: La République, Paris 1984, S. 561-591. Anders als Coquery-Vidrovitch bestreitet Ageron eine mentalitätsprägende Wirkung der Kolonialausstellung von 1931 zugunsten der Akzeptanz des französischen Kolonialengagements in der „France métropolitaine“. Auch er kann jedoch die breite Zustimmung in den Parteien und den Willen der politisch Verantwortlichen zur Ausgestaltung und Nutzbarmachung des Mythos nicht widerlegen.

78 Dieses wie die folgenden Zitate stammen aus der Eröffnungsrede Reynauds, abgedruckt in: Le Temps, 7. 5. 1931.

${ }^{79}$ Zur Entstehungsgeschichte des "kolonialen Mythos“, zu seiner engen Verklammerung mit der republikanischen Tradition und zu den Vorstellungen von "Liberalen" und "Radikalrepublikanern" bis zum I. Weltkrieg: Marshall, French Colonial Myth, S. 11-41; Girardet, Lidée coloniale, S. 3114. 
Jahren hatte der langjährige Minister und Generalgouverneur Indochinas sein Programm entwickelt, das seither zur oft zitierten, wohl einflußreichsten Doktrin französischer Kolonialpolitik zwischen den Kriegen geworden war. Es umfaßte im wesentlichen ein Modell der vertragsmäßigen Beziehung zwischen Kolonisator und Kolonialvolk, basierend auf dem Zusammenspiel europäischen Kapitals und westlicher Intelligenz mit den Rohstoffreserven der Kolonialgebiete - zum Nutzen beider Seiten und der Weltgemeinschaft überhaupt. Als neue, „liberale“ kolonialpolitische Synthese gedacht, propagierte das Konzept die „association“ von Kolonisierten und Kolonisatoren, und zwar in Alternative zu einer Politik der „assimilation“, die Geschichte und Eigencharakter der Eingeborenenvölker vernachlässige. Anvisiert war jedoch im Grunde eine Kompromißlösung, die gleichermaßen die Nachteile konsequenter Assimilierung wie echter Gewährung von Autonomie vermeiden wollte. Auch wenn dabei Reformbedarf insbesondere im Bereich einer allzustark zentralisierten Verwaltung anerkannt wurde, auch wenn die betroffenen Völkerschaften verstärkt zu administrativen Aufgaben herangezogen werden sollten - die politische Emanzipation der kolonisierten Bevölkerung war ebensowenig vorgesehen wie der Ausbau der Repräsentativgremien vor Ort über den Status von Beratungsorganen hinaus, die Zuerkennung von Souveränitätsrechten oder gar der Weg in die Unabhängigkeit. Bezugspunkt für Reformen war und blieb der erweiterte nationale Rahmen des „größeren Frankreich“ .80 Diese Einbindung machte ein Spezifikum der französischen Kolonialdoktrin aus. In Großbritannien fand die Idee vom partnerschaftlichen Anschluß der Dominions an das Mutterland ihre weitgehende Entsprechung in der fortschreitenden Umsetzung von „self-government“ und Gleichberechtigung; im französischen Verständnis dagegen herrschte trotz aller Relativierungen nach wie vor eine stärker auf Homogenisierung und Zentralisierung gerichtete Auffassung vor. ${ }^{81}$

Die Ideen Sarrauts und der damit aktualisierte Traditionsbestand lassen sich durchgehend als Leitlinien auch der Reynaudschen Amtsführung von 1931/32 feststellen.82 Paul Reynaud ging aus von der unilinearen Entwicklung menschlicher Zivilisationen, dachte also in dieser Hinsicht universalistisch und egalitär. Bezeichnend genug, bemühte er in offiziellen Äußerungen, die allgemeinen kolonialpolitischen Zielvorgaben galten, zwar fast durchweg die üblich gewordene Auffassung vom anzustrebenden Assoziationsstatus des „Empire“; daneben vertrat er, zumeist intern, weiterhin die Idee einer zivilisatorischen „assimilation“ der Kolonialvölker durch Frankreich, verstanden als „fusion entre deux civilisati-

80 Sarraut entwickelte sein Konzept in zwei Hauptschriften: Albert Sarraut, La mise en valeur des colonies françaises, Paris 1923; ders., Grandeur et servitude coloniales, Paris 1931. Vgl. zu seinen Thesen: Girardet, L'apothéose, S. 1097-1099; ders., L'idée coloniale, S. 181 f.; Marshall, French Colonial Myth, S. 44-49. Die beste Darstellung zum Verhältnis der Begriffe „Assimilation“ und „Association“ in der französischen Kolonialtheorie und zur Position Sarrauts bietet: Rudolf von Albertini, Dekolonisation. Die Diskussion über Verwaltung und Zukunft der Kolonien 1919 1960, Köln/Opladen 1966, S. 323-357; zum gleichen Thema auch: Raymond F. Betts, Assimilation and Association in French Colonial Theory 1890-1914, New York/London 1961.

81 Vgl. dazu Albertini, Dekolonisation, S. 308.

82 Spuren der Sarraut-Rezeption Reynauds lassen sich direkt nachweisen aufgrund der Notizen, die er aus "Grandeur et servitude coloniales“ anfertigte (vgl. CAOM, Indochine, Nouveau Fonds (N.F.), Carton 267, Dossier 2327(2)). 
ons" ${ }^{83}$ Diese begriffliche Ambivalenz verwies wie bei Sarraut auf eine konzeptionelle: Aus guten Gründen war es nach 1919 kaum mehr opportun, offen eine ,assimilatorische" Mission Frankreichs zu befürworten. Zu sehr hatten die kolonialen „herrschaftstechnischen“ Erfahrungen des ausgehenden 19. Jahrhunderts und neuere wissenschaftliche Erkenntnisse vor allem der Ethnologie eine stärker individualisierende Sehweise "unterlegener" Zivilisationen gefördert und mit ihr neuen Syntheseversuchen rund um den „associations“-Begriff den Weg gebahnt. ${ }^{84}$ Zur konsequenten Abwendung von der alten Doktrin jedoch konnten sich die wenigsten kolonialtheoretischen Reformer durchringen, und weder Albert Sarraut noch Paul Reynaud gehörten zu ihnen. Beider Konzepte behielten assimilatorische Grundzüge, in beiden Fällen bildete die Assoziierung lediglich einen Übergangszustand bis zur endlichen Verwirklichung der erstrebten zivilisatorischen „Fusion“. 85 Dementsprechend hatte es seine systemimmanente Logik, wenn der zivilisationstheoretische Egalitarismus der Politiker vorerst keine Fortsetzung auf praktisch-politischem Feld fand: Die Einführung des allgemeinen Wahlrechts für die indogene Kolonialbevölkerung etwa lehnte Reynaud noch in den späten dreißiger Jahren strikt ab. 86

Es liegt auf der Hand - das wird im folgenden am Beispiel des Krisenschwerpunkts Indochina deutlich werden -, daß ein solches paternalistisch-harmonisierendes Gedankengebäude bereits zu Beginn der dreißiger Jahre nicht mehr in der Lage war, die Realität der konkreten Interessen Frankreichs und der entstehenden Emanzipationsbewegungen im Kolonialreich adäquat zu erfassen. Auch war der Mythos natürlich keineswegs, wie suggeriert, von politischer „Unschuld“, noch nicht einmal in den Absichten jener, die ihn fortschrieben. Im Falle Reynauds waren die vorgetragenen prokolonialen Argumente unterfüttert mit Motiven der allgemeinen Systemstabilisierung und der Neutralisierung zivilisationskritischer Tendenzen im Mutterland.

Nicht in den öffentlichen Stellungnahmen, wohl aber beim vertraulichen „déjeuner intime" mit ausgewählten Pressevertretern kam Reynaud in diesem Sinne deutlich zur Sache. Die Kolonialausstellung sollte mit ihrer Mischung aus Information und Imagination identitätsstiftende Wirkung haben, sollte die in der Öffentlichkeit nicht unangefochtene These vom ökonomischen Nutzen der Kolo-

83 Vor einem Kreis ausgewählter Pressevertreter umschrieb er am Rande der Kolonialausstellung seine Vorstellungen folgendermaßen: „Vous avez à leur [aux Français; S.G.] montrer la difficulté et la complexité de ces problèmes, vous avez à leur dire que l'assimilation, la fusion entre deux civilisations qui, jusqu'ici, ont été surtout juxtaposées, est un problème qui n'est pas un problème de mois ni même un problème d'années." (Rede Paul Reynauds anläßlich des Banketts zur Einweihung der "Section de la Presse" in der "Cité des Informations de l'Exposition Coloniale", o.D. (AN; 74 AP 9)).

84 Zur Abwendung der zeitgenössischen Ethnologie von den Grundannahmen des 19. Jahrhunderts: Girardet, L'idée coloniale, S. 154-174; zu neuen Syntheseversuchen in der französischen Kolonialtheorie bis 1914: Betts, Assimilation and Association, S. $106 \mathrm{ff}$.; Albertini, Dekolonisation, S. $331 \mathrm{ff}$.

85 Zu Sarraut in diesem Sinne: Albertini, Dekolonisation, S. 342 und 345.

s6 So Reynaud in einem Interview mit der Zeitung L'Algérie vom 28. 1. 1937 (AN, 74 AP 10). Im Februar 1938 sprach er sich als kolonialpolitischer Berichterstatter in der Finanzkommission der Assemblée gegen ein Gesetzesprojekt des Abgeordneten Galandon Diouf aus, das zentralafrikanischen Weltkriegsteilnehmern die französischen Bürgerrechte zugestehen sollte (AN, 74 AP 10, Dossier „Projet G. Diouf“). 
nien unterstützen und, in erster Linie, die Bevölkerung auf neue Ziele jenseits des krisengeschüttelten Europa lenken: „Quand on voit toutes les difficultés dans lesquelles nous sommes plongés, vers lesquelles nous allons, s'il n'y avait pas pour le peuple français quelque chose d'en dehors et de très loin, quelque chose qui soit le domaine du rêve, quelque chose qui soit d'un avenir sans limites, eh bien, je crois que le peuple dont vous êtes à la fois les interprètes et les guides, Messieurs de la presse, le peuple subirait dans la cruelle et injuste déception qui l'atteint, une sorte d'affaissement aujourd'hui.“ Und: "c'est l'intérêt général, si vous ne dérivez pas l'opinion publique de la douloureuse Europe, ce pays va finir par sombrer dans la neurasthénie!" 87

Wo den französischen Republikanern des ausgehenden 19. Jahrhunderts die kolonialen Erfolge unter anderem als Beleg für die Überlegenheit der republikanischen Staatsform gegenüber Ancien régime und Kaiserreich gedient hatten, bemühte der liberale Minister im Jahr 1931 einen gleichgerichteten, doch weiterzielenden Gedankensprung. Nicht allein die Legitimität der Republik konnte durch das effektive weltpolitische Ausgreifen erhärtet werden, sondern mehr noch die ungebrochene Innovationskraft des Westens schlechthin: verstärke sich doch dessen Zugriff auf die außereuropäische Welt von Tag zu Tag, sichtbar an den Fortschritten von Flugzeug- und Rundfunktechnik ...88

Der zugrundeliegende Gedankengang verrät wiederum klar den aktualisierenden Rückgriff Reynauds auf eingespielte republikanische Argumentationsschemata. Das Kolonialreich zugleich als Garant und als sichtbarer Beleg für die Erneuerungsfähigkeit des republikanisch-demokratischen Frankreich aus sich selbst: Solche Überlegungen finden sich neben zivilisationstheoretischen und machtpolitisch-ökonomischen Erörterungen bereits im Kolonialdiskurs der frühen Dritten Republik. Ihre Reaktivierung in der "crise des années trente“ zeigt wie das Fortleben des „kolonialen Mythos“ insgesamt einmal mehr das Gewicht mentalitätsprägender politischer Traditionen im politischen Leben Frankreichs zwischen den Kriegen. ${ }^{89}$ Es liegt nahe, mit Blick auf die praktische Politik Paul Reynauds nach den Konsequenzen für konkrete Krisenlösungsstrategien zu fragen. Anhand zweier begrenzter Themenfelder, die zugleich Krisenherde erster Ordnung umfaßten - der Wirtschaftskrise und der kommunistischen Befreiungsbewegungen in Indochina - soll dies im folgenden geschehen.

Die Wirtschaftsstruktur des französischen Kolonialreichs blieb nach dem Ersten Weltkrieg geprägt von den Prinzipien der Assimilation nach innen und der zollpolitischen Abschottung nach außen. Bis zur zweiten Nachkriegszeit trat hier nur ein gradueller Wandel ein, während die prinzipielle Ausrichtung erhalten blieb: Über ein regional variierendes System von Zolltarifen, Begünstigungsregelungen und anderen vertraglichen Bindungen konnten die Kolonialgebiete ihre

87 Manuskript der Rede Paul Reynauds anläßlich des Banketts zur Einweihung der „Section de la Presse“ der Kolonialausstellung 1931, o.D. (AN, 74 AP 9) (Unterstreichung durch Reynaud selbst).

88 So Reynaud in seiner Eröffnungsrede der Kolonialausstellung 1931, abgedruckt in: Le Temps, 7. 5. 1931.

89 Vgl. etwa die gleichgerichteten Ausführungen bei André Tardieu, L'épreuve du pouvoir, Paris 1931, S. XVIII; Albertini, Dekolonisation, S. 321. 
Produkte zwar frei im Mutterland absetzen, hatten jedoch bei der Einfuhr ausländischer Güter hohe Abgaben zu leisten. Besonders eng war die Anbindung der "alten" Kolonien Guadeloupe, Martinique, Guyane, Réunion, aber auch von Madagaskar, Indochina und Algerien. Aufgrund dieser protektionistischen Maßnahmen entwickelten sich die Kolonialgebiete insgesamt bis 1929 zum wichtigsten Handelspartner der Metropole. In der Weltwirtschaftskrise profitierte das Mutterland von den getroffenen Regelungen, da trotz kontrahierender Weltmärkte weiterhin besonders für kaum mehr konkurrenzfähige Produkte etwa der Textilbranche Absatzmöglichkeiten bestanden. Zwar trug eben diese Konstellation in Frankreich zur Konservierung eines gesamtökonomisch überholten Zustands bei, da zukunftsweisende metropolitane Industriesektoren der Metall- und Chemiebranche bis in die Zeit nach 1945 in ihrer Ausweitung gehemmt wurden. Mittelfristig jedoch förderte das niedrige koloniale Preisniveau bei Agrarprodukten und Rohstoffen die wirtschaftliche Erholung des Mutterlands; ein Mechanismus, der sich im übrigen in den meisten Industrieländern einstellte. Weniger günstig präsentierten sich die Folgen der Großen Krise in Frankreichs stark exportorientierten Kolonien selbst, wo der Verfall der Rohstoffpreise und damit der Regionalbudgets gravierende Folgen zeitigte. Allgemein wuchs das ökonomische Gefälle zwischen den industriellen Weltzentren und den Gebieten der „Peripherie“ auf lange Sicht stark an, eine Entwicklung, die den französischen Herrschaftsbereich nicht aussparte. 90

Es war eine nuancierte und keineswegs einheitliche, doch insgesamt ernüchternde Bilanz, die dem neuen Minister bei Amtsantritt im Februar 1931 vorgelegt wurde. Eine ökonomische Tour d'horizon unter anderem durch Indochina, Madagaskar, Französisch-Äquatorialafrika und Französisch-Westafrika zeigte eine weitverbreitete Produktions- und Bankenkrise im Kolonialreich: „La situation générale des colonies, au point de vue économique, est assez grave pour retenir l'attention des Conseils du Gouvernement. La crise générale, qui sévit dans l'ancien comme sur le nouveau continent, ne les a pas épargnées et toutes, sans exception, ont été touchées [...]. En ce qui concerne nos possessions, les conséquences ont été d'autant plus redoutables que la politique coloniale suivie jusqu'à ce jour les avait plus mal préparées à une sérieuse résistance en cas de difficultés [...]. Il y a là, certes, un aveu difficile à faire ouvertement, après surtout qu'une propagande, mieux intentionnée que bien inspirée, a représenté pendant longtemps nos colonies comme des eldorados pourvus de toutes les richesses. " 91

90 Allgemein zu den Folgen der Großen Krise an der „Peripherie“: Dietmar Rothermund (Hg.), Die Peripherie in der Weltwirtschaftskrise: Afrika, Asien und Lateinamerika 1929-1939, Paderborn 1983, darin besonders der einleitende Überblicksaufsatz: Dietmar Rothermund, Einleitung: Weltgefälle und Wirtschaftskrise, in: ebenda, S. 13-35.

Vgl. speziell zur wirtschaftlichen Bedeutung des Kolonialreichs für Frankreich im Spannungsfeld politischer Steucrung und privater Interessen die Arbeiten von Jacques Marseille, besonders: ders., Empire colonial et capitalisme français. Histoire d'un divorce, Paris 1984; einen knappen Extrakt der hier vorgetragenen Ergebnisse bietet der Autor in: ders., Colonisation, décolonisation et capitalisme (1880-1960). Un divorce à la française, in: Vingtième Siècle 4 (1984), S. 39-48. Hinweise auch bei: Albertini, Dekolonisation, S. 314-317; Coquery-Vidrovitch, Colonisation française, S. 227-257.

91 Note für den Minister: „Situation économique des colonies, 1er février 1931“, 31.1. 1931, S. 1 und 4. (CAOM, Affaires politiques, 2622). Gleicher Tenor auch in bezug auf das wirtschaftlich 
In der Tat trafen die Folgen der Krise das französische Kolonialreich in durchaus unterschiedlichem, wenngleich bislang noch nicht ganz eindeutig differenzierbarem Ausmaß, das nicht zuletzt vom Grad der Verflechtung der jeweiligen Territorien mit dem internationalen Bankensystem und dem Welthandel abhing. Besonders betroffen waren wohl neben Marokko und Französisch-Äquatorialafrika auch das bis dahin prosperierende Indochina. ${ }^{92}$ Aufgrund seiner Handelsüberschüsse mit dem Fernen Osten lange Zeit in der Lage, das gesamtfranzösische Handelsbilanzdefizit entscheidend zu verringern, fungierte das Land als ertragreicher Investitionsmarkt für Kapital aus dem Mutterland. Um 1930 traten deutliche Krisenphänomene auf, so der Verfall der wichtigen Reis- und Kautschukkurse und der Rückgang des Werts der Gesamtexporte um 30\% im Jahr 1930, um 39\% im Folgejahr. Als nach fünf Krisenjahren die Exportraten wieder stiegen, war die ökonomische Kraft des Landes nichtsdestoweniger dauerhaft geschädigt, und gravierende soziale Umschichtungen waren erfolgt. Der Niedergang der Reiswirtschaft hatte zum Ruin großer, mittelständischer und kleiner Plantagenbesitzer geführt, hatte die bürgerliche Rentiersschicht in ihrem Lebensnerv getroffen und in der Frage der Hypotheken- und Kreditregelung ein nicht unerhebliches soziales Protestpotential gegen Staat und europäisches Kapital entstehen lassen. Die Pauperisierung der Landbevölkerung erreichte in weiten Teilen des Landes katastrophale Ausmaße.93

Der Krisenstrategie des Ministers, die sich an der Gesamtheit der Kolonialgebiete zu orientieren hatte, lagen einige einfache Prinzipien zugrunde; zusammengenommen gaben sie ein weitgehend anti-interventionistisches, wirtschaftsliberales Glaubensbekenntnis ab. Das Vertrauen in die Selbstheilungskräfte des Marktes galt Reynaud als oberstes Gebot, die schließliche Autoregulation des Systems als dessen unweigerliche positive Folge: „La crise est une maladie. Contre la maladie, l'organisme, livré à lui-même, secrète des anti-toxines, l'abaissement des prix qui entraîne la restriction de la production, dont l'excès est la cause du mal. Et surtout, bénéfice durable -il élimine les producteurs les moins adaptés à la lutte pour la vie. Enfin, la baisse des cours facilite les achats aux consommateurs atteints par la crise. [...] Tel est le processus naturel. Mais l'Etat intervient-il? Prend-il des mesures pour maintenir les cours? Alors les anti-toxines ne sont pas secrétées. "94 Staatliche Eingriffe waren dennoch schon um des Erhalts des sozialen Friedens willen unerläßlich, hatten aber „im Sinne der ökonomischen Gesetze“ zu erfolgen. Ange-

schwächste Kolonialgebiet Frankreichs: „Gouvernement général de l'Afrique occidentale française. Rapport politique et administratif. Année 1931“, 27.9. 1932 (CAOM, Affaires politiques, 538).

92 Vgl. die Einschätzungen bei Coquery-Vidrovitch, Colonisation française, S. 227-232; dics., L'Afrique coloniale française et la crise de 1930: crise structurelle et genèse du sous-développement, in: Revue française d'histoire d'outre-mer 63 (1976), S. 386-424; Pierre Brocheux/Daniel Hémery, Indochine. La colonisation ambiguë (1858-1954), Paris 1995, hier: S. $245 \mathrm{ff}$.

93 Ebenda, S. 166-173 und 260-274.

94 Redetext Paul Reynauds unter dem Titel "La tâche de notre colonisation devant la crise mondialc“, vermutlich 14.6.1931 (AN, 74 AP 9). Reynaud zur Wirtschaftskrise und ihren Auswirkungen im Kolonialreich: JO, Chambre des Députés, Débats parlementaires, 2e séance du 23 février 1931, S. 1075-1080; zum Thema auch seine Stellungnahme vor der zuständigen Parlamentskommission (Archives de l'Assemblée Nationale, Commission de l'Algérie, des colonies et des protectorats, Procès-verbal du 13 février 1931). 
wandt auf die Wirtschaftskrise in den Kolonien bedeutete dies, nicht etwa nach US-amerikanischem Vorbild das verfallende Preisniveau künstlich zu stützen. Vielmehr mußte es darum gehen, den anpassungsfähigsten Produzenten in den Kolonialländern das Überleben am Markt zu ermöglichen und mit ihnen die Modernisierung der Produktionsstrukturen zu fördern: „En agissant ainsi, nous remplissons notre devoir d'orienteurs. Nous rappelons aux producteurs coloniaux que, sur le marché mondial, la bataille du prix de revient sera sévère et que, seuls, ceux qui se seront imposé les dures disciplines de la rationalisation auront des chances de la gagner. “95

In der politischen Praxis mündeten diese Prinzipien in ein Spektrum traditioneller Mittel, das Reynaud einsetzte und unterstützte. Es umfaßte insbesondere die Kreditvergabe an die private Wirtschaft vor Ort und den Einsatz protektionistischer Maßnahmen: Ziel war die Regelung und Begünstigung der kolonialen Produktion über die Anwendung von Kontingentierungen, Vorzugsregelungen und Subventionen. Ein Bündel gesetzgeberischer Maßnahmen führte u. a. zur Bereitstellung mittelfristiger Kredite an Pflanzer und zur prononcierten Förderung jener Betriebe, die neue „wissenschaftliche Anbaumethoden“ einsetzten. Gefördert wurden Infrastrukturverbesserungen mit dem Ziel, die exportwirtschaftliche Erschließung voranzutreiben und Kapitalinvestitionen wieder attraktiv zu machen. Eingeleitet wurde auch ein ambitiöses Programm zur Erschließung neuer Reisanbauflächen in Indochina. Dazu gewährte der französische Gesetzgeber den Kolonialgebieten während der kurzen Amtsperiode Reynauds die Genehmigung zur Aufnahme von Investitionsanleihen in Höhe von insgesamt über 5 Milliarden Francs. ${ }^{96}$ Flankierend sollte eine rigide Austeritätspolitik mittels Einsparungen und Steuererhöhungen das Budgetgleichgewicht in den oft gravierend geschädigten Kolonialhaushalten wiederherstellen. ${ }^{97}$

Budgetdeflation, Protektionismus, Maßnahmen zur Marktkonzentration und zur Rationalisierung der verbliebenen Kolonialproduktion, schließlich Einsatz von rückzahlbaren Finanzhilfen, die den Neuaufbau langfristig den Kolonialgebieten selbst überließen - das waren die wesentlichen krisensteuernden Instrumente der Amtszeit Paul Reynauds. Sie zeigen den Minister auf halbem Wege zwischen dem verstärkten Rückgriff auf liberale Wirtschaftstheorien, wie er in

95 Redetext Paul Reynauds "La tâche ..." (AN, 74 AP 9).

96 Entsprechend den Gesetzen vom 22.2. und 10.7.1931 entfielen davon auf Französisch-Westafrika, Indochina, Madagaskar, Togo und Kamerun 3,9 Mrd., auf Neu-Kaledonien 95 Mio., auf Französisch-Äquatorialafrika 822 Mio., schließlich auf La Réunion, Martinique, Guadeloupe und Guyana 359 Mio. Die als Teil des Gesamtprojekts vorgesehenen 197 Mio. Francs für Somalia, Oceanien und Kamerun wurden während der Amtszeit Reynauds nicht mehr verabschiedet („Note pour le ministre“, 26. 2. 1932; CAOM, Affaires politiques, 2622, Dossier VI/4). Reynaud rechtfertigte seine Anleihepolitik vor der Kammer: JO, Chambre des Députés, Débats parlementaires, 2e Séance du 23 février 1931, S. 1075f.; zum Ziel der Wahrung kolonialer Absatzmärkte: ebenda, 2e Séance du 27 mars 1931, S. 2298.

Dazu auch Coquery-Vidrovitch, Colonisation française, S. 230-234; Brocheux/Hémery, Indochine, S. 270-274.

${ }_{97} \mathrm{Vgl}$. hierzu insbesondere seine telegraphischen Ermahnungen wegen unsolider Finanzführung: Reynaud an Cayenne, No. 29 v. 15. 2. 1932; Reynaud an Hanoi, No. 175 v. 16. 2. 1932: „[...] Votre premier souci en dehors maintien sécurité doit être avoir finances saines." (CAOM, Télégrammes, Cabinet du ministre des colonies, 598) sowie sein Zirkular an alle Kolonien und Mandatsgebiete vom 20. 7. 1931 (ebenda, 599). 
Ökonomenkreisen im Umfeld der Krise aufkam, und der forcierten Hinwendung zum Interventionsstaat, den ein André Tardieu proklamiert hatte98: Anders als einflußreiche neo-liberale Reformer vom Format des Unternehmers Edmond Giscard d'Estaing verschloß sich der interventionsbereite Reynaud nicht dem Gedankengang, notleidenden Wirtschaftszweigen des Mutterlands ein subventionierendes "débouché colonial“ zu verschaffen, statt sie durch den Markt eliminieren zu lassen. ${ }^{99}$ Sie zeigen ihn auf halbem Wege aber auch zwischen einer "politique de pillage" alten Stils einerseits und einer Politik wirklichen Strukturwandels in den Kolonien andererseits. Propagiert durch eine kleine Gruppe von Kolonialunternehmern um Paul Bernard, konnte letztere Option vor dem Zweiten Weltkrieg keinen Eingang mehr ins Regierungshandeln finden, und auch Paul Reynaud förderte sie keineswegs. Nicht die Industrialisierung der Kolonien oder die forcierte Entwicklung ihrer inneren Märkte setzte sich durch, sondern Kolonialprotektionismus und nutzenorientierte „Aufgabenteilung " $z$ wischen Industrieländern und kolonialen Rohstoffproduzenten: „le repli sur l'Empire“. ${ }^{100}$ Manche Wurzeln einer "Spirale der Unterentwicklung" sind hier zu suchen. So stand die intensive Anleihepolitik Frankreichs wohl mehr noch als die internationale Rezession am Beginn eines jahrzehntelangen Abhängigkeits- und Verschuldungsprozesses, der vor dem Zweiten Weltkrieg keine befriedigende Lösung mehr erfuhr. Zudem war die praktizierte Politik, das zeigt das Beispiel Indochina, noch nicht einmal frei von kontraproduktiven Effekten: Die staatlicherseits favorisierte Anleihepolitik zwang die Kolonialverwaltung vor Ort, gleichzeitig einen Großteil ihres Budgets zur Unterstützung von Handel und Großbesitz wie auch zur Erfüllung des Schuldendienstes aufzuwenden. Dieses Unterfangen war nicht ohne Erhöhung der Steuerlasten möglich, trug damit wiederum zur fortschreitenden Pauperisierung der Landbevölkerung bei und förderte so die Ausweitung jener politischen Instabilität, die unter anderem gerade bekämpft werden sollte. ${ }^{101}$

Noch erschien die sich anbahnende Überlastung des kolonialen Systems Frankreichs beherrschbar, und zwar nach Ansicht der überwiegenden Mehrheit der Verantwortlichen in Politik und Kolonialadministration: Paul Reynaud machte hier keine Ausnahme. Im Sommer 1931 hatte die Wirtschaft des Mutterlands die nahende Depression kaum zu spüren bekommen. Eine ökonomisch-politische Restaurationspolitik mittels begrenzten staatlichen Kapitaleinsatzes in den Kolonien schien zugleich wirtschaftlich machbar und erfolgversprechend im Sinne der

98 Jackson, Politics of depression, S. 14f., 27-34.

99 „[...] le débouché colonial est pour la France chaque jour plus important, parce que 25 p. 100 du textile français s'écoule dans les colonies"; JO, Chambre des Députés, Débats parlementaires, $2^{e}$ Séance du 27 mars 1931, S. 2298. Zur "stratégie libérale“ um Giscard d'Estaing: Marseille, Empire colonial, S. 218-239.

100 Zur Eingrenzung der Positionen in der Diskussion um die angemessene „mise en valeur“ der Kolonien seit Anfang der dreißiger Jahre: Marseille, Empire colonial, S. 240-258; ders., Colonisation, décolonisation, S. $45 \mathrm{f}$.

101 Daniel Hémery, Aux origines des guerres d'indépendance vietnamiennes: pouvoir colonial et phénomène communiste en Indochine avant la Seconde Guerre mondiale, in: Le Mouvement social 101 (1977), S. 3-35, hier: S. 17; bis Ende 1936 stieg der Anteil, den die Zinszahlungen aus den erhaltenen Anleihen am Gesamthaushalt der Kolonie ausmachten, auf mehr als ein Fünftel an. Im höchstverschuldeten Gebiet, in Französisch-Westafrika, machte die Zinslast bereits ein Viertel des Budgets aus; vgl. Hémery, Aux origines, S. 17-19; Zitat: Brocheux/Hémery, Indochine, S. 267. 
Wahrung bzw. Wiederherstellung des erhofften ökonomischen Nutzens. Noch auch gingen die maßgeblichen Politiker und Beamten davon aus, daß die politische Unruhe im Kolonialreich, die durch die Auswirkungen der Wirtschaftskrise gesteigert worden war, zu meistern sei. Mit ausschlaggebend für diesen Eindruck war die Tatsache, daß der offene politische Protest in den betroffenen Gebieten noch nicht - wie dann nach 1945 - geschlossene und kontinuierliche Form angenommen hatte.

Als Paul Reynaud Anfang Mai 1931 die Pariser Kolonialausstellung eröffnete, ging er kaum auf den neuen Krisenherd Indochina ein. Die Misere der dortigen Landbevölkerung verschwieg er wohlweislich ebenso wie die Tatsache, daß das Land zum gleichen Zeitpunkt Schauplatz gewaltsamer Repressionsmaßnahmen der Kolonialmacht war, wie es sie seit den Anfängen der Erschließung noch nicht gekannt hatte. Verbrannte Dörfer, Gefangenenerschießungen und Verhaftungen durch die Sûreté waren seit Herbst 1930 an der Tagesordnung. Nichts wäre wohl mehr geeignet gewesen, den harmonisierenden Duktus der Festreden als Fassade bloßzustellen, die Ausstellung selbst als "Schattentheater" 102 zu decouvrieren. Daß das offiziell verbreitete Bild kaum mehr zur Erfassung der komplexeren Realität in der Lage war, wurde indes nur seitens der politischen Linken thematisiert. Auf das schreiende Mißverhältnis von Mythos und Wirklichkeit machte wiederum in aller Deutlichkeit nur der PCF über eine wenig beachtete Gegenausstellung, über Demonstrationen und Flugblattaktionen in Vincennes aufmerksam. ${ }^{103}$

Es war nicht auf einen direkten kausalen Zusammenhang zurückzuführen, daß die expositorische Apotheose des kolonialen Gedankens von 1931 zeitlich zusammenfiel mit einem ersten Höhepunkt der Aktivitäten nationalistisch und kommunistisch inspirierter Unabhängigkeitsbewegungen. Inbesondere von Indochina, neben Algerien der bedeutendste Teil des Empire, nahmen die Befreiungsbestrebungen ihren Ausgang, und dies in einem Ausmaß, welches die Region von da an zum "neuralgischen Punkt“ im Kolonialreich machte. Seit Mitte der zwanziger Jahre hatte sich die Lage kontinuierlich zu Ungunsten Frankreichs zugespitzt. Die Forderung nach sofortiger Unabhängigkeit des Landes war um 1927 bereits Allgemeingut jener nationalistischen Geheimorganisationen geworden, die seither vermehrt durch gewaltsame Aktionen auf sich aufmerksam machten. Vorläufiger Höhepunkt der Terroraktionen rechter Provenienz war die Ermordung der Offiziere des Truppenstützpunkts Yen-Bay am 10. Februar 1930 gewesen, die die nationalistische Partei "Viet Nam Quoc Dan Dang“ zu verantworten gehabt hatte. Die Gründung der kommunistischen Partei Vietnams wenige Tage zuvor hatte unterdessen bereits eine neue Phase der antikolonialen Bewegung eingeleitet, die bis 1936 in die völlige politische Entmachtung bzw. Umorientierung der vietnamesischen Nationalbewegung mündete. Symbolhaft dafür traten ab Frühjahr 1930 kommunistisch inspirierte und organisierte Streik- und Demonstrationswellen neben die nationalistischen Gewaltaktionen und lösten sie allmählich ab. In mehreren Regionen Nord-Annams verloren dabei die Kolonialbehörden die poli-

102 Ageron, L'exposition coloniale, S. 576.

103 Coquery-Vidrovitch, Colonisation française, S. 223-225. 
tische Kontrolle zugunsten von „Sowjets“ und erlangten sie nicht vor Mitte 1931 nach dem Einsatz von Truppen der Fremdenlegion wieder. Verurteilungen wie Gefängnisstrafen gingen in die Tausende, und erst 1932 konnte diese schwerste Krise seit der kolonialen Inbesitznahme Indochinas äußerlich beigelegt werden. An die Wurzeln der politisch-ökonomischen Malaise gelangte man damit und auch in der Folge nicht: politischen Niederschlag fand dies bis 1936 im Aufstieg der kommunistischen Partei zum dominierenden innenpolitischen Gegner Frankreichs in Indochina. 104

Das Interesse der Pariser Parlamentarier an den Vorgängen in Südostasien hielt sich in Grenzen und erwachte zumeist erst dann, wenn gewaltsame Unruhen Handlungsbedarf signalisierten. So hatte die letzte große Kammerdebatte zum Indochina-Problem im Gefolge des Massakers von Yen-Bay zwischen dem 6. und 27. Juni 1930 stattgefunden, und sie blieb bis 1946 die letzte, die sich mit dem politischen Status des Landes in grundlegender Form beschäftigte. ${ }^{105}$ Auch Reynaud kam in der Abgeordnetenkammer während seiner Amtszeit nahezu ausschließlich im Rahmen von Budgetdebatten zu Wort: ein sprechendes Indiz für die eher untergeordnete Bedeutung, die die Materie insgesamt im Beratungskalender einnahm, zumal in Zeiten, in denen mit der drohenden deutsch-österreichischen Zollunion, der Reparationsproblematik und der Mandschurei-Krise andere internationale Fragen das Interesse dauerhaft banden.

Am 23. Februar 1931, bereits knapp einen Monat nach der Amtseinführung, hatte Reynaud vor der Kammer zum Thema Stellung zu nehmen. Anlaß war die gewaltsame Auflösung dreier Protestzüge in der Provinz Annam im September 1930 durch die Kolonialmacht, bei der nach Einsatz eines Bombenflugzeugs über hundert Tote auf seiten der Demonstranten zu beklagen gewesen waren. Wie schon im Juni 1930 kam Kritik an der Regierungspolitik in grundsätzlicher und aggressiv vorgetragener Form aus den Reihen der neun kommunistischen Abgeordneten, in differenzierter Weise aber auch von sozialistischer und radikalsozialistischer Seite. Reynaud verteidigte die gouvernementale Position in einer für seine Verhältnisse ungewöhnlich martialischen, ja rüden Sprache. Gleichzeitig stellte er sich damit ostentativ in die Tradition französischer Indochinapolitik, wie sie seit 1930 von den Regierungen der „Union nationale“ unter Tardieu und Steeg verfolgt worden war.

Nach Auffassung einer Mehrheit in der SFIO und bei den Radikalsozialisten stand die zivilisatorische Mission Frankreichs außer Frage. Stein des Anstoßes war hier indes regelmäßig die politisch-praktische Umsetzung des hohen Anspruchs. Anders als die Antikolonialisten im PCF wandte man sich klar gegen die sofortige Unabhängigkeit von Gebieten, die man wie im Falle Indochinas noch

104 Coquery-Vidrovitch, Colonisation française, S. 214, 267-271, Zitat: S. 268; Daniel Hémery, Aux origines; ausfübrlich zu den Anfängen des Kommunismus in Indochina: ders., Révolutionnaires vietnamiens et pouvoir colonial en Indochine. Communistes, trotskystes, nationalistes à Saigon de 1932 à 1937, Paris 1975. Zur Entstehung der vietnamesischen Nationalbewegung: Jean Chesneaux, Entwicklungsstufen der nationalen Bewegung Vietnams 1862-1940, in: Rudolf von Albertini (Hg.), Moderne Kolonialgeschichte, Köln/Berlin 1970, S. 389-399. Die neueste Gesamtdarstellung der französischen Kolonisation in Südostasien bieten: Brocheux/Hémery, Indochine, hier: S. 275324.

${ }^{105}$ Hémery, Aux origines, S. 6; Albertini, Dekolonisation, S. 320. 
nicht für reif dafür hielt. Statt dessen strebte man langfristig eine echte Assoziationslösung nach dem Vorbild der englischen Dominions an. ${ }^{106}$ Léon Blum formulierte die durchaus ambivalente Parteilinie knapp so: „Le jour où j'aurai l'impression que dans un pays comme l'Indochine, nous ne nous maintenons plus que par la force et peut-être par la terreur, je deviendrai, moi, partisan de l'évacuation totale. " 107

Kein Zweifel bestand dagegen für Paul Reynaud daran, daß Frankreich in Indochina zu bleiben hatte, kein Zweifel auch, daß die dort entstehende kommunistische Bewegung mit aller Kraft zu bekämpfen war: „Je ne suis pas partisan, en ce qui me concerne, des manifestations d'énergie verbale, mais je dis: entre les communistes et nous, c'est une question de force, et nous sommes décidés à rester les plus forts. [...] Le communisme, c'est parfaitement clair, veut chasser la France de l'Indochine. Voilà la bataille entre lui et nous. Cette bataille nous la mènerons jusqu'au bout contre lui." Eine dosierte Mischung aus Repression und begrenzten Reformen hatte seiner Meinung nach handlungsleitendes Prinzip zu sein, immer unter der Vorgabe möglichst starker Präsenz vor Ort, um die Ordnung aufrechtzuerhalten und nicht den Eindruck zu erwecken, Reformen aus bloßer Furcht einzuleiten. ${ }^{108}$ Alle Zeichen von Schwäche waren zu vermeiden, die Deportation von Aufständischen, die sich des Mordes schuldig gemacht hatten, war beizubehalten; Gnadenersuchen hatten nur in Einzelfällen berücksichtigt zu werden: „[...] une clémence globale, collective, aveugle, qui serait considérée par les populations comme un signe de faiblesse, ce serait, messieurs, un aliment de plus dans la lutte contre nous." 109 Ein Bestand an rasch einzuleitenden Reformmaßnahmen sollte die Bevölkerung daneben für die Anziehungskraft der kommunistischen Propaganda unempfänglich machen: die Schaffung lokaler Budgets in der Kolonie, alimentiert aus dem direkten Steueraufkommen der eingeborenen Bevölkerung und kontrolliert durch lokal gewählte Gremien; die Reform der unpopulären Salzsteuer; schließlich die Einführung einer Erbschaftssteuer auf hohe Nachlaßsummen. Langfristig sollten überdies die Karriereaussichten eingeborener Beamter in der Kolonialverwaltung verbessert und die innere Struktur des Ministerialapparats trotz aller Finanznöte effektiver gestaltet werden.110

Obgleich nur als erste Maßnahmen gedacht und bald unter anderem durch den auf Indochina entfallenden Teil der geschilderten finanztechnischen Maßnahmen ergänzt, lassen schon die improvisierten Ansätze den Geist auch der folgenden Reformen erkennen. Es ging Reynaud und den Verantwortlichen in seinem Umkreis darum, das koloniale System so zu modifizieren, daß es imstande war, die ökonomisch-politische Krise zu überdauern. Eine grundlegende Revision der bestehenden Machtverhältnisse etwa im Sinne der Annäherung an ein Regime des „self-government" nach englischem Vorbild war dagegen nicht beabsichtigt. Bezeichnend dafür war das Vorgehen von Minister und Bürokratie im Zuge der administrativen Vorbereitung der "großen“ Anleihen von 1931: Achtete man doch

106 Hémery, Aux origines, S. 7-9: Albertini, Dekolonisation, S. 357-368.

${ }_{107} \mathrm{JO}$, Chambre des Députés, Débats parlementaires, 2e Séance du 23 février 1931, S. 1090.

${ }_{108}$ Ebenda, S. 1075-1080, Zitat: S. 1076.

${ }^{109}$ Ebenda, S. 1077 (Zitat), 1078, 1089.

110 Ebenda, S. 1079 f. 
sorgsam darauf, im Gesetzestext keine Befugniserweiterung der kolonialen Conseils Généraux vorzunehmen, welche auf dem Feld der Budgetgewährung eine unkontrollierbare Machtverschiebung zu Ungunsten der Generalgouverneure vor Ort bewirkt hätte. ${ }^{111}$ Überhaupt, so der Minister, sei es gefährlich, zu schnell zu weitgehende Freiheiten zu gewähren, „car il est impossible ensuite de revenir en arrière." ${ }^{112}$ Die strenge Begrenzung in der Fortentwicklung des wirtschaftlichen Status quo fand somit ihr Gegenstück im politischen Bereich: „Pour ce qui est de l'Indochine, il faut simplement rechercher si par un ensemble de mesures d'ordre administratif, fiscal, économique on peut ramener un certain calme dans les esprits." 113

Im Verlauf des Jahres 1931 und insbesondere nach einer vierwöchigen Indochinareise im Herbst des gleichen Jahres entfaltete Reynaud entlang dreier Hauptachsen die Reformanstrengungen. Eine umfangreiche Verwaltungsreform hatte zum Ziel, die schlimmsten Mißstände im Bereich der einheimischen Verwaltungsspitzen, des Mandarinats, auf dem Gebiet der Justiz und in der französischen Administration selbst zu beheben. In den Folgejahren wurden daraufhin über tausend Notabeln abgesetzt, deren willkürliche Amtsführung und Steuereintreibung regelmäßig Anlaß zu Unmut in der Bevölkerung gegeben hatten; noch während seiner Ostasienreise ordnete Reynaud eine praxisnähere Ausbildung französischer Beamter und die Erhöhung der Zahl der Aufnahmen in die „Ecole coloniale" an. ${ }^{114}$

In einem zweiten Zugriff versuchte man dem Pauperisierungsproblem im wesentlichen über die Neuordnung des landwirtschaftlichen Kreditwesens, den rechtlichen Schutz des Kleinbesitzes und ein ehrgeiziges Programm von Wasserbauten Herr zu werden. Aufs engste verbanden sich hier volkswirtschaftliche und politische Motive: Über Investitionen in Bewässerungs- und Dammsysteme in Millionenhöhe wurden bis 1940 Hunderttausende von Hektar neuer Reisanbaufläche erschlossen - ein Vorgehen, das nach dem treffenden Wort von Daniel Hémery auch den Zweck hatte, „politische Dämme“ gegen die Ausbreitung der kommunistischen Ideologie zu errichten. Ambivalent blieben die aus der Anleihe vom 22. Februar 1931 anschubfinanzierten Maßnahmen dennoch: Da echte Strukturreformen bis zum Zweiten Weltkrieg unterblieben, konnte bei stetig wachsender Bevölkerung das ohnehin defizitäre Versorgungsniveau lediglich ge-

111 "Note confidentielle pour le Ministre", 13. 2. 1931; Brief Reynauds an den Präsidenten der Abgeordnetenkammer, 14.2. 1931 (CAOM, Affaires politiques, 2622, Dossier „Emprunts. Projets de loi et lois autorisant des emprunts pour Colonies, 1930-32“).

112 Reynaud in Anspielung auf das Verhältnis zwischen Eingeborenen und Europäern in den holländischen Kolonien (Haut Conseil Colonial, Procès-verbal de la séance du 18 mai 1931; CAOM, Indochine N.F., 631).

113 Ebenda.

114 Vgl. hierzu den Abschlußbericht des Directeur des Affaires Politiques im Kolonialministerium, Gaston Joseph, „Conclusions d'ensemble sur le voyage du Ministre des Colonies en Indochine, Décembre 1931. Etablies par le Directeur", 28. 12. 1931, S. 24-26, 31-55 (CAOM, Indochine N.F., 54, Dossier 635). Leider gewährten mir die Nachkommen Josephs keinen Einblick in den Nachlaß des langjährigen hochrangigen Kolonialbeamten, der in Aix-en-Provence verwahrt liegt.

Vgl. auch die detaillierte Auflistung der durchgeführten und noch geplanten Reformmaßnahmen durch Generalgouverneur Pasquier: „Annexe au rapport sur le programme des réformes en Indochine. Textes nécessaires aux réalisations prévues" (CAOM, Indochine N.F., 2682). Zum Hintergrund: Hémery, Aux origines, S. 15; ders., Révolutionnaires vietnamiens, S. 31-33. 
halten werden. Der Wettlauf gegen die voranschreitenden Unterentwicklungssymptome in der ländlichen Bevölkerung war dagegen bis 1940 nicht mehr zu gewinnen. ${ }^{115}$

Drittens schließlich wurden unter Reynaud politische Maßnahmen in die Wege geleitet, die darauf abgestellt waren, die Zusammenarbeit zwischen Kolonialmacht und intellektuellen, administrativen wie ökonomischen Eliten des Landes zu festigen. Teils unter Aufnahme radikalsozialistischer Forderungen gestand Reynaud die Ausweitung des bestehenden Wahlzensus zum höchsten beratenden Kolonialgremium vor Ort, dem „Conseil Colonial“, zu und gewährte die zahlenmäßige Gleichstellung von Franzosen und Asiaten. Eine Befugniserweiterung des Gremiums war damit nicht verbunden.116 Außerdem erhielt Indochina einen Sitz im "Conseil Supérieur des Colonies". ${ }^{117}$ Diese Ausweitung kam dem einheimischen Großgrundbesitz zugute, der seinen Vertretungsanspruch befriedigt sah. ${ }^{118}$ Die Heimsendung des in Frankreich unterrichteten annamitischen Kaisersohns Bao-Dai wurde durch Reynaud bereits vorbereitet und kam schließlich im September 1932 zustande. Die dahinterstehenden Motive sind kennzeichnend für das gesamte verfassungspolitische Reformwerk: „[...] il semblerait naturel que le retour du prince coincidat avec l'avènement d'un régime de gouvernement qui offrirait plus d'apparence d'autonomie, tout en laissant à la puissance protectrice la faculté de contrôler et même d'inspirer les actes de gouvernement. " ${ }^{119}$ So trug dieser Teil der Reformpläne eher den Charakter klientelpolitischer Zugeständnisse an die bürgerliche Verfassungsbewegung und eine schmale Oberschicht als den Stempel effektiver politischer Innovation.

Wiederum bezog Reynaud eine Position des abwartenden, defensiven Reformismus, nunmehr stark beeinflußt durch die rigiden Positionen des konservativen Generalgouverneurs Pasquier. ${ }^{120}$ Reynauds individualisierend-demokratisches politisches Denken hatte klare, aus zivilisationstheoretischen Überzeugungen erwachsene Grenzen. Eine Feststellung, die um so schwerer wiegt, als der kolonialtheoretische, volkswirtschaftliche und politische Diskurs der Zeit jeweils theore-

115 Joseph, „Conclusions d'ensemble...“, S. 58-86 (CAOM, Indochine N.F., 54, Dossier 635). Zum allgemeinen Rahmen: Brocheux/Hémery, Indochine, S. 270-274; Hémery, Aux origines, S. 14-17.

116 Vgl. dazu neben dem Bericht Josephs: Reynaud an Hanoi, No. 774 v. 29. 7. 1931 und Reynaud an Hanoi, No. 1324 v. 25. 12. 1931 (CAOM, Télégrammes. Cabinet du ministre des colonies, 598).

$\mathrm{Zu}$ den Kompetenzen des „Conseil Colonial de Cochinchine“ zählten im wesentlichen die Beschlußfassung im Bereich der Verwaltung kolonialer Besitztitel und der öffentlichen Arbeiten. Die Verabschiedung des Budgets der Kolonie war jedoch an die Zustimmung des Generalgouverneurs gebunden. Die Wahl der asiatischen Mitglieder vollzog sich seit 1922 nach Zensuswahlrecht, das die einheimische Besitz- und Verwaltungselite begünstigte (Brocheux/Hémery, Indochine, S. 400).

117 Joseph, „Conclusions d'ensemble...“, S. 10 f. (CAOM, Indochine N.F., 54, Dossier 635); vgl. dazu etwa die Forderung Daladiers in der Parlamentsdebatte vom Juni 1930: JO, Chambre des Députés, Débats parlementaires, Séance du 27 juin 1930, S. $2749 \mathrm{ff}$.

118 Hémery, Révolutionnaires vietnamiens, S. $32 \mathrm{f}$.

119 Vgl. Reynauds und Piétris Stellungnahmen in: Haut Conseil Colonial. Procès-verbal de la séance du 18 mai 1931 (CAOM, Indochine N.F., 631).

120 Der Reformplan Pasquiers liegt vor in Form eines umfangreichen Schreibens an den Minister: Pasquier an Reynaud, 23. 3. 1931 (CAOM, Indochine N.F., 2682).

Über die Bedenken des Generalgouverneurs, die Überzahl französischer Vertreter im Conseil Colonial abzubauen - „parce que cet élément [français], en dehors même de raisons politiques évidentes, est le plus apte à user des pouvoirs qui lui sont attribués“ (ebenda, S. 15) - setzte sich Reynaud allerdings hinweg. 
tische Alternativen, Minderheitsoptionen freilich, bereitgehalten hätte. Was es ihm leicht machte, das vorgegebene Traditions- und Machtgefüge des „Empire“ zu akzeptieren und weiterzudenken, war mehr als bloßer Opportunismus. Zweifellos war zum einen die Beharrungskraft eines komplexen Systems ausschlaggebend, die immerhin so groß war, daß selbst die aufbruchsgestimmte Kolonialpolitik der Volksfront bis Mitte 1937 nicht mehr sehr weit von jener ihrer bürgerlichen Vorgängerregierungen seit 1930 entfernt war. Die Imperative ökonomischer Krisenbewältigung und die machtpolitische Bedeutung des Kolonialreichs in der Konkurrenz Frankreichs mit den faschistischen und totalitären Mächten Europas bedingten die relative Kontinuität der französischen Kolonialpolitik zwischen 1930 und 1940, ja darüber hinaus. 121 Daneben bot die um 1930 dominierende Version des "kolonialen Mythos" den gesellschaftspolitischen Prärogativen eines Rechtsliberalen genügend naheliegende Anknüpfungspunkte: Reynaud brauchte seine paternalistisch-harmonisierende, von Elitenbewußtsein und Fortschrittsdenken bestimmte Sicht im Grunde nur über die „France métropolitaine“ hinaus anzuwenden und entsprechend dem Modell von der Hierarchie der Zivilisationsstufen $z u$ akzentuieren.

Die Attitüde medienwirksamer Modernität, die er pflegte, und die ihn als ersten Kolonialminister Frankreichs per Schiff und Flugzeug nach Indochina führte ${ }^{122}$, kontrastierte mit den Maßnahmen harter Repression, die in seiner Amtszeit und mit seiner Billigung erfolgten. An diesem Gesamtbefund ändert auch sein Einschreiten gegen besonders eklatante Menschenrechtsverletzungen der Kolonialarmee nichts. ${ }^{123}$ Mit dem Kolonialressort hatte die Dritte Französische Republik ein Ministeramt zu bieten, in dem ein Politiker mehr als in anderen Gefahr lief, mit den kompromittierenden Seiten der Macht in Berührung zu geraten. Auch Paul Reynaud entging dieser Gefahr nicht.

121 Hémery, Aux origines, S. 32-34.

122 Umfangreiches Material zur Indochinareise des Ministers vom 16. 10.-24. 11. 1931 findet sich in: CAOM, Indochine N.F., 634-636.

123 Vgl. Reynaud an Hanoi, No. 486 v. 9. 5. 1931 (CAOM, Télégrammes. Cabinet du ministre des colonies, 598). 